\title{
有机太阳能电池用聚合物给体材料的研究进展
}

\author{
叶怀英 ${ }^{a, b}$ 李 文*,a 李维实 ${ }^{*, b}$ \\ ( ${ }^{a}$ 湘潭大学材料与光电物理学院 湘潭 411105) \\ ( ${ }^{b}$ 中国科学院上海有机化学研究所材料科学研究室 上海 200032)
}

\begin{abstract}
摘要 有机太阳能电池由于质轻、价廉、柔性, 受到人们的广泛关注. 开发性能优异的聚合物给体材料, 是近期有机太 阳能电池研究的主流方向之一. 迄今为止, 已经成功开发出各种各样具有优秀的给体性质的共轭聚合物. 基于这些材 料制备的有机太阳能电池器件, 已经突破 $9 \%$ 的光电转换效率. 按照聚合物给体材料的主链结构分类, 综述了近年来这 方面的研究进展. 对一些受到普遍关注的材料, 从设计思想、性能剖析到器件制备和性能, 做了详细的介绍, 以期能够 深层次理解材料的化学结构-凝聚态结构-性能间的基本规律，为今后的材料研发提供有价值的参考.
\end{abstract}

关键词 有机太阳能电池; 给体; 受体; 窄带隙材料; 共轭聚合物; 光电转换

\section{Progress in Polymeric Electron-Donating Materials for Organic Solar Cells}

\author{
Ye, Huaiying ${ }^{a, b}$ \\ Li, Wen*,a \\ Li, Weishi ${ }^{*, b}$ \\ ( ${ }^{a}$ Faculty of Materials and Optoelectronic Physics, Xiangtan University, Xiangtan 411105) \\ $\left({ }^{b}\right.$ Laboratory of Materials Science, Shanghai Institute of Organic Chemistry, Chinese Academy of Sciences,
}

Shanghai 200032)

\begin{abstract}
Organic solar cells (OSCs) have attracted an extensive attention due to their light-weight, low cost and flexible features. Exploitation of novel polymeric donating materials is one of the mainstreams in the field. To date, a variety of conjugated polymers with excellent electron-donating properties have been developed. Based on these materials, power conversion efficiency of OSCs has reached to $9 \%$. This review classifies these materials based on the chemical structures of the repeating units, and summarizes their progress accordingly. A number of representative materials, which have received much attention, are highlighted from the aspects of designing strategy, properties, device fabrication and performance. It is anticipated to penetrate more deeply the basic relationships among the chemical structure-packing structure-property, which could provide valuable information for the future materials exploitation.
\end{abstract}

Keywords organic solar cell; donor; acceptor; narrow bandgap material; conjugated polymer; photoelectric conversion

作为取之不尽、用之不竭、无污染的可再生与清洁 能源，太阳能的充分利用是解决目前人类所面临的能源 短缺和环境污染等问题的根本途径. 实现廉价的太阳能 发电, 是人类梦棩以求的追求. 在过去几十年中, 以硅 基为代表的无机半导体太阳能电池技术得到充分的发 展, 已经实现实用化. 但是, 由于其生产工艺复杂、成本 高、不易实现大面积器件以及制造过程中带来的严重环 境污染，限制了硅基太阳能电池的大规模推广应用. 20
世纪 80,90 年代出现的染料敏化和有机基太阳能电池 (organic solar cells, OSCs), 采用廉价的光伏活性材料, 为太阳能发电开辟了新的道路. 染料敏化太阳电池采用 无机纳米晶半导体和有机光敏剂相结合, 其能量转换效 率超过 $10 \%$, 但是由于其高效率的电池需要使用液态电 解质和高腐蚀性氧化还原介质 $\left(\mathrm{I}^{3-} / \mathrm{I}^{-}\right)$, 给实用化带来不 便. 而有机太阳能电池的活性层基本采用固态的有机/ 聚合物半导体材料, 具有一些独特优势: (1)有机材料质

\footnotetext{
*E-mail: liwen@xtu.edu.cn; liws@mail.sioc.ac.cn

Received April 6, 2011; revised August 18, 2011; accepted September 20, 2011.

Project supported by the National Natural Science Foundation of China (Nos. 20974119, 90922019, 21074147), the Science and Technology Commission of Shanghai Municipality (No. 09PJ1411700), the Scientific Research Foundation for the Returned Overseas Chinese Scholars, State Education Ministry, and the One Hundred Person Project of the Chinese Academy of Sciences.

国家自然科学基金(Nos. 20974119, 90922019, 21074147)、上海市浦江人才计划基金(No. 09PJ1411700)、教育部留学回国人员科研启动基金和中国科 学院百人计划资助项目.
} 
量轻、柔韧性好; (2)有机材料可以进行化学设计、裁剪 和合成, 无资源存量的限制; (3)电池器件制备工艺简单, 可采取印刷、喷墨、打印等溶液加工法, 成本低; (4)容 易制备大面积和柔性器件. 因此, 有机太阳能电池自从 发明 ${ }^{[1,2]}$ 以来, 引起了科学家的极大兴趣 ${ }^{[3]}$.

有机太阳能电池通常的器件结构见图 1 所示, 是将 有机光伏活性层夹在两个功函数不同电极间, 一电极常 为透明的 ITO 阳极, 另一为金属阴极, 常用 $\mathrm{Al}, \mathrm{Ca}$ 等. 活性层和电极之间, 可以根据需要加入其他的修饰层, 比如 PEDOT:PSS, $\mathrm{LiF}, \mathrm{ZnO}, \mathrm{TiO}_{x}$ 等. 有机光伏活性层的 结构, 目前主要有 2 种: 双层 ${ }^{[1]}$ 和本体异质结结构 ${ }^{[2]}$. 但 无论哪种结构, 其活性层的材料都包含电子给体 (Electron-donating, D) 材料和电子受体(Electron-accepting, A)材料. 常见的电子给体材料是具有共轭结构的 小分子化合物或者聚合物, 而电子受体材料则为富勒烯 或酰亚胺的衍生物, 比如 $[6,6]$-phenyl- $\mathrm{C}_{61}$-butyric acid methyl ester $\left(\mathrm{PC}_{61} \mathrm{BM}\right)$, [6,6]-phenyl- $\mathrm{C}_{71}$-butyric acid methyl ester ( $\left(\mathrm{PC}_{71} \mathrm{BM}\right)$ 等. 光电转换的基本原理是: 光激 发活性层材料分子至激发态, 即生成所谓的激子; 而后, 激子通过传递转移至 $\mathrm{D} / \mathrm{A}$ 的交界处时, 受到 $\mathrm{D}$ 和 $\mathrm{A}$ 电 子亲和势不同的诱导, 产生电荷分离; 之后, 分离后的 正负电荷载流子通过各自的传输通道, 达到对应的电 极, 完成光电转换过程. 由此可见, 高效率有机太阳能 电池必须满足的条件是: (1)活性层材料对太阳光有充分 吸收能力; (2)活性层的微结构必须有利于电荷分离和载 流子传输.

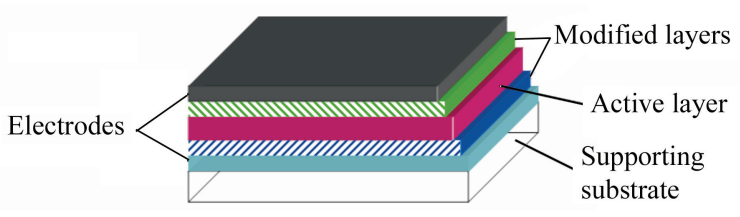

图 1 有机太阳能电池结构

Figure 1 Device configuration of an organic solar cell

从有机太阳能电池的发展历史来看, 新材料的开发 非常关键. 每次好的材料研制成功, 都大大提高了器件 性能, 特别是光电转化效率. 自从 1995 年 Wudl 等 ${ }^{[4]}$ 发 明了 PCBM 类优秀的电子受体材料之后, 新材料的开发 较为活跃的是电子给体领域. 相比小分子化合物, 共轭 聚合物具有许多优势: 一维延伸的 $\pi$ 共轭体系有利于激 子和电荷载流子的传递; 容易通过聚合物的结构设计来 调控其光吸收能力等物性; 具有较好的溶液成膜性. 因 此, 聚合物型电子给体材料引起广大科研工作者的极大 兴趣, 新结构、新合成方法层出不穷, 优秀的材料不断 涌现, 着实提高了光电转化效率, 目前已超 $9 \%{ }^{[5]}$, 推进 了有机太阳能电池技术的进步. 本文按照聚合物主链的
类型分类，举例说明这方面的研究进展，更主要是介绍 材料背后设计理念，这对进一步的材料研制有着重要的 参考价值.

\section{1 传统型共轭聚合物给体材料}

\section{1 聚苯乙烯撑[Poly(p-phenylenevinylene), PPV]}

自从 1990 年 Brroughes 等 ${ }^{[6]}$ 发现 PPV 的电致发光性 能以来, PPV 是在有机光电领域研究的最早、也最为广 泛和深入的聚合物材料. 由于 PPV 主链的刚性很强, 无 修饰的 PPV 具有难溶难熔的性质, 一旦形成很难加工, 从而给后处理和加工过程带来很大困难. 对此, 通常通 过修饰有助溶支链的办法来解决. 基于此策略, 已经开 发出多种可溶性 PPV 材料 ${ }^{[7]}$. 这些聚合物具有优良成膜 性质，性能稳定，且易于合成，被认为是最有可能实现 商业化的聚合物半导体材料之一.

最具代表性 PPV 聚合物之一为 MEH-PPV [MEH: 2-methoxy-5-(2'-ethylhexyloxy) $]^{[8]}$, 通过侧链支化的烷氧 长链提高溶解性能. MEH-PPV 通常采用 Gilch 方法合成 (Scheme 1), 这种合成方法反应条件比较温和, 得到的 聚合物分子量也大, 多数聚合反应过程中会有凝胶或沉 淀产生. 2000 年, Ferraris 等 ${ }^{[9]}$ 发现加入定量的 4-甲氧基 苯酚作为链转移剂, 可以有效地调控聚合物分子量, 表 明 Gilch 聚合具有阴离子聚合特征. MEH-PPV 是一种发 橙光的聚合物, 能带宽度大约为 $2.1 \mathrm{eV}$, 具有较强的可 见光吸收能力, $200 \mathrm{~nm}$ 厚的薄膜对可见光的吸收可达 90\%, 因此较早被用于有机太阳能电池的制备. 1993 年 Sariciftci 等 ${ }^{[10]}$ 制备的第一个共轭聚合物 $/ \mathrm{C}_{60}$ 双层光伏器 件、1995 年 Heeger 等 ${ }^{[2]}$ 首次制备的共轭聚合物/ $/ \mathrm{PC}_{61} \mathrm{BM}$ 本体异质结光伏器件、以及 1995 年 Hall 等 ${ }^{[2 b]}$ 报道的全 聚合物型本体异质结光伏器件, 都使用了 MEH-PPV 作 为电子给体材料.
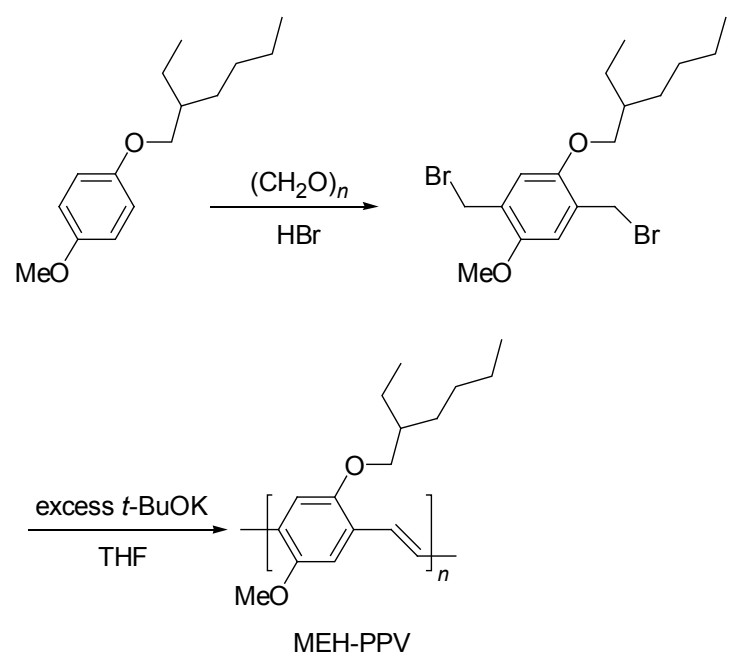

Scheme 1 
另一种广泛使用的 PPV 聚合物为 MDMO-PPV [MDMO: 2-methoxy-5-(3,7-dimethyloctyloxy)], 其结构 特征是共轭主链苯上一取代基为甲氧基, 另一为末端支 化的长链烷氧基团. MDMO-PPV 也经常作为一种电子 给体材料用于有机太阳能电池的制备. 例如, Shaheen 等 ${ }^{[11]}$ 用 MDMO-PPV:PC ${ }_{61} \mathrm{BM}(1: 4, w / w)$ 的共混体系作 为光伏活性层制备器件, 测得性能参数为 $J_{\mathrm{SC}}=5.23$ $\mathrm{mA} \cdot \mathrm{cm}^{-2}, V_{\mathrm{OC}}=0.82 \mathrm{~V}, \mathrm{PCE}=2.5 \%$. Veenstra 等 ${ }^{[12]}$ 则利 用 MDMO-PPV 作为电子给体材料和作为受体材料的聚 合物共混制备全聚合物型本体异质结器件, 其性能参数 为 $J_{\mathrm{SC}}=1.80 \mathrm{~mA} \cdot \mathrm{cm}^{-2}, V_{\mathrm{OC}}=1.3 \mathrm{~V}, \mathrm{FF}=0.32, \mathrm{PCE}=$ $0.75 \%$. 由于 MDMO-PPV 主链苯环的两个取代基各不 相同, 相邻单元的连接方式决定了侧链取代基的空间取 向, 因此产生了取代基的立构规整性问题. Tajima 和 Hashimoto 等 ${ }^{[13]}$ 利用 Wittig-Hornor 反应合成了具有完全 立构规整性的 MDMO-PPV, 同时也合成了立构不规则 的 MDMO-PPV, 作为性能参照物(Scheme 2). 研究表 明，相比立构不规则的聚合物，立构规整性的 MDMO-PPV 具有较高的结晶度. 将这聚合物用于太阳 能电池器件中, 也显示了明显不同的器件性能 ${ }^{[7 \mathrm{~d}]}$. 由立 构规整的 MDMO-PPV 和 $\mathrm{PC}_{61} \mathrm{BM}$ 共混体系制备的本体 异质结电池器件, 表现出性能参数为 $J_{\mathrm{SC}}=6.2 \mathrm{~mA} \cdot \mathrm{cm}^{-2}$,
$V_{\mathrm{OC}}=0.71 \mathrm{~V}, \mathrm{FF}=0.70, \mathrm{PCE}=3.1 \%$. 而相同条件下, 利 用立构不规则的 MDMO-PPV 制备的电池器件光电转化 率只有 $1.7 \%$. 这个例子生动的说明聚合物侧链取向的 重要性.

除了在主链苯环上修饰烷氧链以提高聚合物的溶 解性能之外, 许多科研工作还致力于从多方面对 PPV 主链进行改性, 以求获得更优异的聚合物光电材料. 例 如, 在苯环上引入可以产生空间位阻效应的的双苯基, 则得到发蓝光的 PPV 聚合物(DP-PPV) ${ }^{[14]}$. 一般 PPV 类 聚合物是 $\mathrm{p}$ 型半导体材料，而 Heeger 等 ${ }^{[15]}$ 将强吸电子能 力的 $\mathrm{CN}$ 基团引入 $\mathrm{PPV}$ 主链, 得到 $\mathrm{n}$ 型的聚合物半导体 材料 CN-PPV. 性能研究表明 CN-PPV 具有较低的 HOMO 和 LUMO 能级, 适合作为电子受体材料, 和其 他聚合物电子给体材料配合使用，制备全聚合物型太阳

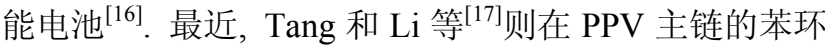
上通过 Wittig-Horner 反应引入两个三苯胺基团, 得到聚 合物 P2. 相比没有三苯基胺侧链的聚合物 $\mathbf{P} 1\left(E_{\mathrm{g}}=2.3\right.$ $\mathrm{eV}), \mathbf{P 2}$ 具有较窄的带隙宽度 $\left(E_{\mathrm{g}}=2.0 \mathrm{eV}\right)$, 以 $\mathbf{P} 2 / \mathrm{PC}_{61} \mathrm{BM}$ 制备的本体异质结电池器件光电转化率为 $0.45 \%$, 高于相同条件下 $\mathbf{P 1} / \mathrm{PC}_{61} \mathrm{BM}$ 的电池器件 $(\mathrm{PCE}=$ $0.09 \%$ ), 表明三苯基胺侧链的引入, 确实提高了聚合物 的光伏性能.
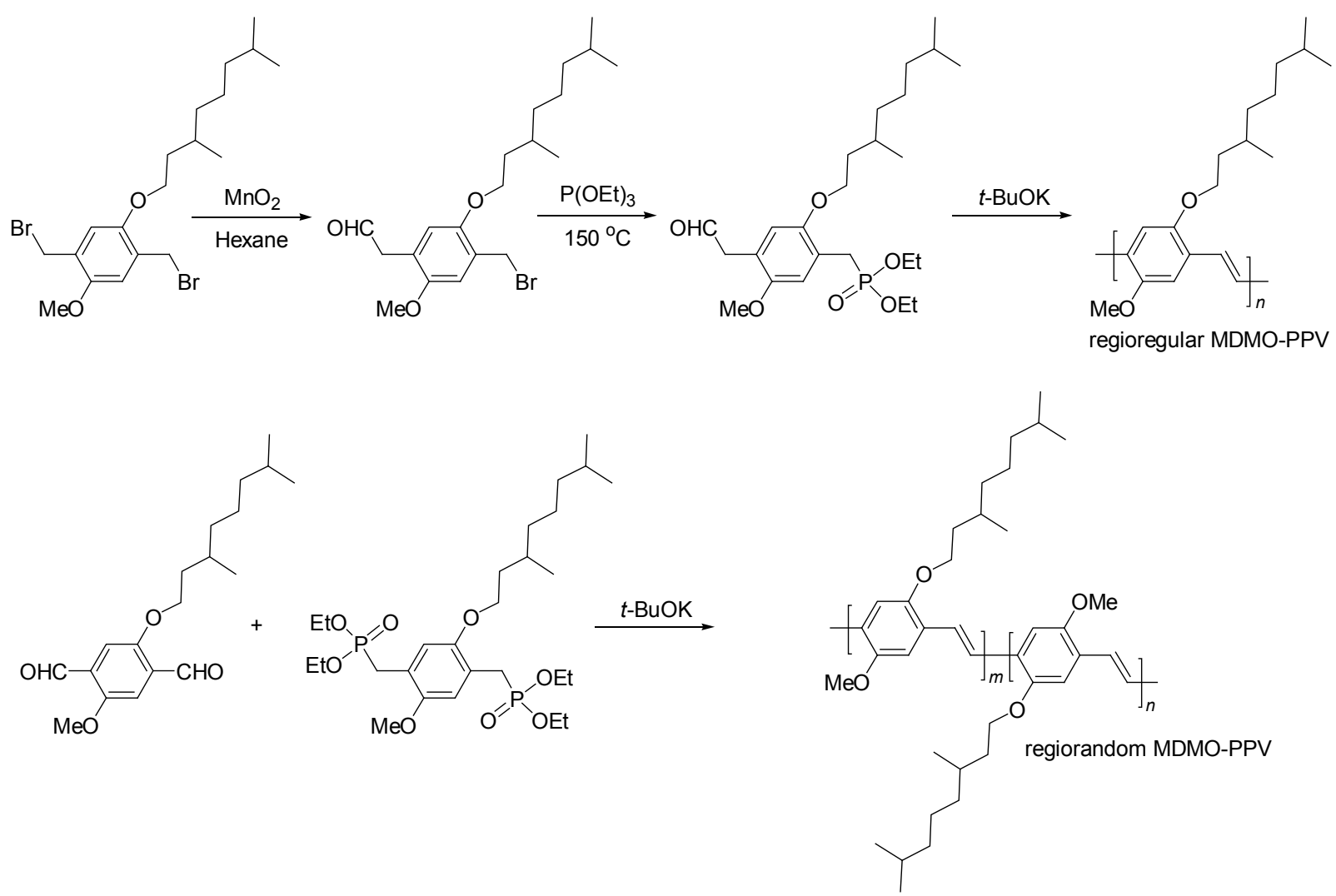

Scheme 2 


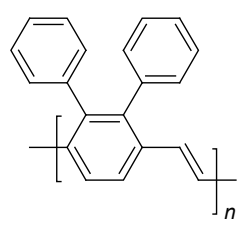

DP-PPV

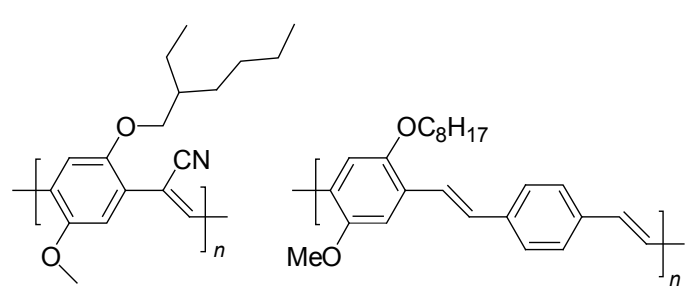

CN-PPV
P1

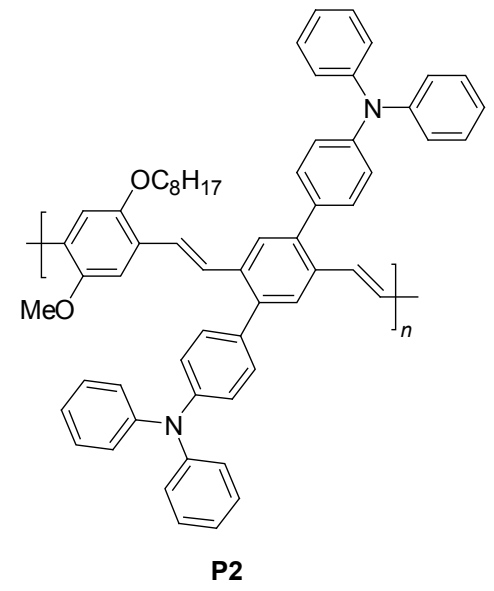

以 MEH-PPV 和 MDMO-PPV 为代表的 PPV 聚合物 在早期(1995 2004年)有机太阳能电池研究中是主导性 的聚合物给体材料. 从上面的例子可以看出, 基于此类 聚合物和 $\mathrm{PC}_{61} \mathrm{BM}$ 共混体系制备本体异质结电池器件, 其光电转换效率达到 $2 \% \sim 3 \%$. 此后, 随着聚噻吩材料 的开发, PPV 聚合物材料由于其吸收光谱和空穴迁移率 都不如具有立构规整性的聚(3-已基) 噻吩 [Poly(3hexylthiophene), P3HT], 逐步退出主导地位.

\section{2 聚噻吩(Polythiophene, PT)}

聚噻吩是一类重要的聚合物光电材料, 具有非常强 的光吸收能力, 吸收范围接近红外区域, 也具有较高的 载流子迁移能力, 广泛用于有机光电器件、金属防腐涂 层、传感探测电极等. 早期报道聚噻吩没有取代基, 由 于主链结构具有刚性, 这些聚噻吩大多不溶不熔, 给后 期加工造成难度 ${ }^{[18]}$. 为解决这一问题, 1986 年 Elsenbaumer 等 ${ }^{[19]}$ 在噻吩的 3 位引入烷基, 发现当烷基 链大于正丁基时, 得到的聚噻吩(P3AT) 可溶于四氢呋 喃、甲苯、二氯甲烷等有机溶剂. 1984 年, Glenis 等 ${ }^{[20]}$ 首次将电化学聚合的聚噻吩夹在 $\mathrm{Al}$ 和 $\mathrm{Au}$ 电极间, 测试 其光伏性能. 1994 年 Heeger 等 ${ }^{[21]}$ 发现聚噻吩和 $\mathrm{C}_{60}$ 之间 可以发生有效的光诱导电荷分离, 并用于制备双层电池 器件, 而 Roman 等 ${ }^{[22]}$ 制备了首例聚噻吩和 $\mathrm{C}_{60}$ 的本体异 质结电池器件. 此后, 大量的研究工作蓬勃开展, 器件 性能超过 PPV 类材料制备的器件, 光电转化效率达到 约 $5 \%{ }^{[23]}$ 以及最近的 $6.5 \%{ }^{[24]}$, 从而使聚噻吩成为有机太 阳能电池主导的电子给体材料.

在聚噻吩类材料中, 噻吩环通过 2,5 位连接, 形成 共轭主链, 因此尚余 3,4 位, 可以加以修饰. 但是, 由于 3,4 双取代的噻吩相邻链节之间位阻较大, 使得相邻噻 吩环的共平面性变差, 降低主链的共轭程度, 从而不利 于其光电性能. 因此, 在已报道的聚噻吩材料中, 同时 在 3,4 位修饰的几乎没有, 而聚 3-烷基噻吩(P3AT)则占 据了大半江山. 在此类材料, 除了聚合度和分子量分布

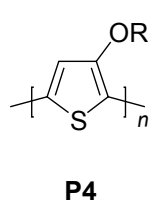

$\begin{array}{ll}\text { P3HT } & R=\text { hexyl }\end{array}$

P3OT $R=$ octyl

P3DT $\quad \mathrm{R}=$ decyl

P3DDT $R=$ dodecyl

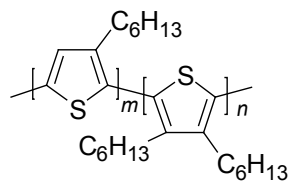

P3

P4

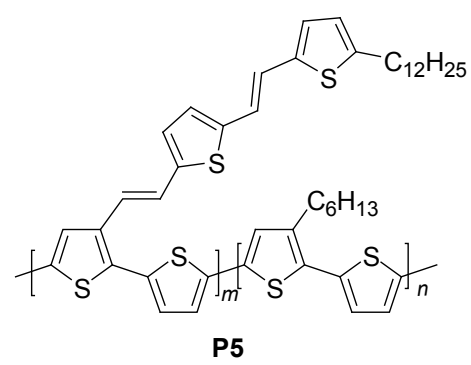

外, 有两大结构因素影响材料的性能, 一为烷基的长度. 对此, 2007 年 Nguyen 和 Hoppe 等 ${ }^{[25]}$ 系统研究了侧链链 长和后处理过程的影响(表 1). 他们利用立构规整的 $\mathrm{P} 3 \mathrm{AT}$ 和 $\mathrm{PC}_{61} \mathrm{BM}$ 的共混体系, 在相同条件下制备本体 异质结电池器件, 发现未经热处理的器件, 性能都很差 $(\mathrm{PCE}<1 \%)$, 而且随着侧链的增长短路电流及光电转换 效率逐渐增大. 他们对每种器件都做了热处理工艺的优 化, 表 1 列出对最佳的热处理过程工艺. 从中可以看出, 侧链的链长越长, 所需要的热处理温度越低. 作者认为 这是由于聚合物的结晶温度随着链长的变长而降低, 而 且 $\mathrm{PC}_{61} \mathrm{BM}$ 也越容易扩散. 这些数据也表明, $\mathrm{P} 3 \mathrm{HT}$ 具有 最佳的器件性能. 实际上, Heeger 等 ${ }^{[23 a]}$ 在 2005 年时已 经报道 $\mathrm{P} 3 \mathrm{HT}$ 和 $\mathrm{PC}_{61} \mathrm{BM}$ 的本体异质结器件经过 $130{ }^{\circ} \mathrm{C}$ 热处理 $30 \mathrm{~min}$, 器件的性能参数为 $V_{\mathrm{OC}}=0.63 \mathrm{~V}, J_{\mathrm{SC}}=$ $9.5 \mathrm{~mA} \cdot \mathrm{cm}^{-2}, \mathrm{FF}=0.68$, 光电转换效率达到 $5 \%$. 同年, Carroll 研究小组 ${ }^{[23 b]}$ 也报道了 $5 \%$ 的效率, 2 年之后更是 提高至 $6 \%{ }^{[24 a]}$. 
表 1 P3AT: $\mathrm{PC}_{61} \mathrm{BM}$ 本体异质结电池器件热处理前后的电池 性能 ${ }^{[25]}$

Table 1 Performances of P3AT:PC ${ }_{61} \mathrm{BM}$ bulk heterojunction solar cells as prepared and after optimized anneal

\begin{tabular}{clcccc}
\hline P3AT & $T /{ }^{\circ} \mathrm{C}, t / \mathrm{min}$ & $\begin{array}{c}J_{\mathrm{SC}} / \\
\left(\mathrm{mA} \cdot \mathrm{cm}^{-2}\right)\end{array}$ & $\begin{array}{c}V_{\mathrm{OC}} \\
\mathrm{mV}\end{array}$ & FF & $\begin{array}{c}\mathrm{PCE} / \\
\%\end{array}$ \\
\hline \multirow{2}{*}{ P3BT } & - & 1.29 & 300 & 0.31 & 0.1 \\
& $160,0.5$ & 1.87 & 500 & 0.29 & 0.27 \\
P3HT & - & 1.8 & 750 & 0.31 & 0.42 \\
& 140,5 & 6.6 & 600 & 0.64 & 2.55 \\
P3OT & - & 1.97 & 600 & 0.38 & 0.45 \\
& 125,4 & 5.55 & 500 & 0.33 & 0.91 \\
\multirow{2}{*}{ P3DT } & - & 2.58 & 550 & 0.36 & 0.54 \\
& 75,5 & 4.22 & 550 & 0.45 & 1.05 \\
P3DDT & - & 2.9 & 600 & 0.38 & 0.65 \\
\hline
\end{tabular}

影响 P3AT 性能的另一结构因素为侧链的立构规整 度(Regioregularity, RR). 对此, 有两个研究小组开展了 详细的研究. Kim 等 ${ }^{[26]}$ 比较了三种不同立构规整 $(\mathrm{RR}=$ $95.2 \%, 93 \%, 90.7 \%) \mathrm{P} 3 \mathrm{HT}$ 和 $\mathrm{PC}_{61} \mathrm{BM}$ 配合制备的本体异 质结电池器件, 发现在同等条件下刚制备的电池光电转 化效率分别 $2.1 \%, 1.3 \%$ 和 $0.9 \%$, 经过在惰性氛围下 140 ${ }^{\circ} \mathrm{C}$ 热处理 $2 \mathrm{~h}$, 三种器件的效率分别为 $2.4 \%, 1.8 \%$ 和 $0.7 \%$. 他们由此得出结论为立构规整度高的聚合物有 利于光电转化. 结合其他的结构分析研究, 他们认为立 构规整度高的聚合物, 容易生成规整的凝聚态结构, 即 结晶度高, 从而提高空穴载流子的传输能力. 同时, 立 构规整度高的 P3HT, 由链与链间相互作用引起的吸收 谱带也较强, 从而增强了材料的光吸收能力. 两者的共 同作用, 使得器件的电流密度和填充因子都得到提高, 而开路电压基本和立构规整度无关, 从而提高了器件的 光电转换效率. 他们对器件的制备和后处理工艺做进一 步的优化, 利用 RR 为 $95.2 \%$ 的 P3HT 得到 PCE 为 $4.4 \%$ 的器件. 而 Fréchet 研究小组 ${ }^{[27]}$ 有意将 3,4二取代的噻吩 和3-已基噻吩(物质的量比为 $1: 24$ )共聚得到聚合物 P3, 降低聚合物的立构规整性 $(R R=91 \%)$. 他们利用 $\mathbf{P 3}$ 和 相同条件下制备的高立构规整度的 P3HT (RR > 96\%) 和 $\mathrm{PC}_{61} \mathrm{BM}$ 配合制备本体异质结器件, 发现这两个器件在 $150{ }^{\circ} \mathrm{C}$ 下热处理 $30 \mathrm{~min}$, 器件性能差不多( $\mathrm{PCE}$ 分别为 $4.4 \%$ 和 $4.3 \%$ ). 处理 $300 \mathrm{~min}$ 后, 利用 P3 聚合物的器件 性能比较稳定, PCE 还保持 $3.5 \%$, 但利用高立构规整度 的 P3HT 器件的 PCE 跌至 $2.5 \%$, 说明低立构规整度具 有更高的热稳定性. 此后, 他们 ${ }^{[28]}$ 对立构规整度对器件 性能的影响进行系统的研究. 他们指出 Kim 等 ${ }^{[26]}$ 的研 究不充分, 未对每种材料制备的器件分别做工艺优化. 为此, 他们重新挑选了三种具有不同立构规整度 $(R R=$
$96 \%, 90 \%, 86 \%$ )但分子量和分子量分布相似的 P3HT, 和 $\mathrm{PC}_{61} \mathrm{BM}$ 配合制备本体异质结电池器件, 并对三个器 件分别进行热处理工艺的优化. 他们发现器件达到效率 最高时，在 $150{ }^{\circ} \mathrm{C}$ 下热处理所需的时间不同: 采用 $\mathrm{RR}$ 96\% P3HT 的器件只需 $30 \mathrm{~min}$, 而采用 RR $90 \%$ 和 RR $86 \%$ P3HT 的器件各需 60 和 $120 \mathrm{~min}$, 但最优时三个器 件都取得相同的光电转换效率( $\mathrm{PCE}=3.8 \% \sim 3.9 \%)$. 他 们还发现, 采用 RR $86 \%$ P3HT 的器件, 热稳定性非常 好, 在 $150{ }^{\circ} \mathrm{C}$ 下热处理超过 $10 \mathrm{~h}$, 效率还保持在 $3 \%$ 左 右. 反而, 采用 RR $96 \%$ P 3 HT 的器件, 在 $150{ }^{\circ} \mathrm{C}$ 下热处 理, 随着时间的延长, 器件效率急剧下降, $5 \mathrm{~h}$ 后效率低 于 $2.5 \%$.

除了 P3AT 之外, 还有各式各样聚噻吩材料被报道. 这里, 值得一提的是 $\mathbf{P 4}{ }^{[29]}$ 和 $\mathbf{P 5} 5^{[30]}$ 两类聚合物. $\mathbf{P 4}$ 的侧 链采取更具有给电子能力的烷氧基，导致其吸收谱带较 P3AT 红移, 有利于太阳光的吸收. 但是不幸的是, $\mathbf{P 4}$ 的 $\mathrm{HOMO}$ 能级比 P3AT 高, 降低其和 $\mathrm{PC}_{61} \mathrm{BM}$ 配合制备的 本体异质结电池器件的开路电压. P5 的侧链采取共轭的 手段，延伸两个噻吩乙烯撑基团，使得整个聚合物在 $350 \sim 650 \mathrm{~nm}$ 之间具有非常宽广的吸收光谱，而且整个 区域的吸收系数都处于高水平. 相比之下，典型的 P3HT 材料在 350 480 nm 之间的吸收较弱. 而且, P5 具有比 P3HT 较低的 HOMO 能级. 利用 $\mathbf{P 5}$ 作为电子给 体材料, 和 $\mathrm{PC}_{61} \mathrm{BM}$ 配合制备本体异质结电池器件, 器 件性能优于同等条件下利用 P3HT 的器件.

\section{2 窄带隙聚合物给体材料}

从上述的综述可以看出, 采用聚噻吩, 特别是 P3HT 作为电子给体材料之后, 有机太阳能电池的光电 转换效率达到 $5 \% \sim 6 \%$, 但依然不能满足实用化的要求. 其中, 聚噻吩光吸收能力的局限也是导致低效率的原因 之一. 一般聚噻吩的能隙是 $1.9 \sim 2.0 \mathrm{eV}$, 只能够吸收 $650 \mathrm{~nm}$ 以下的太阳光. 而在太阳辐射能中, 有相当部分 的能量(约 44\%)位于近红外区, 不能被聚噻吩吸收利用. 因此, 最近十年来, 材料开发的重点方向之一是发展窄 带隙的聚合物给体材料，以期能更好地利用近红外区域 的太阳光能. 所谓窄带隙, 通常指小于聚噻吩的带隙. 此类聚合物最早的合成报道见于 1992 年 Havinga 等 ${ }^{[31]}$ 的工作，而将此用作太阳能电池给体材料则始于 2001 年 Brabec 和 Janssen 研究小组 ${ }^{[32]}$ 的工作. 实现窄带隙的 策略, 主要有: (1)提高主链的醌式结构, (2)提高主链的 共平面性, 即刚性, (3)采取富电子基团 $\mathrm{D}$ 和缺电子基团 $\mathrm{A}$ 的交替共聚. 鉴于目前在有机太阳能电池用的窄带隙 聚合物主要是基于 $\mathrm{D}-\mathrm{A}$ 交替共聚物，本章节以受体基团 为分类标准, 总结这方面的研究进展. 


\section{1 基于芳环并噻二唑基团}

芳环并噻二唑, 比如苯并噻二唑和噻吩并噻二唑, 是常用的缺电子基团, 用于构筑各类窄带隙的聚合物. 2001 年, Janssen 等 ${ }^{[32 b]}$ 合成 P6, 并首次将窄带隙聚合物 用作太阳能电池的给体材料. P6 主链含苯并噻二唑、噻 吩和吡咯基团, 其薄膜光谱吸收峰位于 $608 \mathrm{~nm}$, 能隙为 $1.6 \mathrm{eV}$. Winder 和 Sariciftci 等 ${ }^{[33]}$ 应用此聚合物和 $\mathrm{PC}_{61} \mathrm{BM}$ 配合制备本体异质结器件, 得到性能为: $V_{\mathrm{OC}}=$ $0.72 \mathrm{~V}, I_{\mathrm{SC}}=3.1 \mathrm{~mA} \cdot \mathrm{cm}^{-2}, \mathrm{FF}=0.37, \mathrm{PCE}=1 \% .2003$ 年, Anderson 等 ${ }^{[34]}$ 开发了引人注目的主链含芴、噻吩和苯并 噻二唑基团的窄带隙共聚物 P7 $\left(\mathrm{R}^{1}=2\right.$-ethylhexyl, $\mathrm{R}^{2}=$ hexyl), 并初步和 $\mathrm{PC}_{61} \mathrm{BM}$ 配合制备电池器件, 获得光电 转换效率为 $2.2 \%$. Cao 等 ${ }^{[35]}$ 在 2004 年也报道了类似的共 聚物 $\left(\mathrm{R}^{1}=\mathrm{R}^{2}=\mathrm{octyl}\right)$, 测试所得的光电性能也差不多. 之后, 他们 ${ }^{[36]}$ 将芴基团两个苯环间的桥连 $\mathrm{C}$ 换成 $\mathrm{Si}$, 得 到共聚物 $\mathrm{P8}\left(\mathrm{R}^{1}=\mathrm{R}^{2}=\right.$ octyl, $\left.M_{\mathrm{n}}=79000, \mathrm{PDI}=4.2\right)$, 并 和 $\mathrm{PC}_{61} \mathrm{BM}$ 配合制备太阳能电池, 光电转换效率为 $5.4 \%$ $\left(V_{\mathrm{OC}}=0.90 \mathrm{~V}, J_{\mathrm{SC}}=9.5 \mathrm{~mA} \cdot \mathrm{cm}^{-2}, \mathrm{FF}=0.507\right) . \mathbf{P 8}$ 之所以 比 P7 优秀, 得益于: (1)其吸收谱带更处在近红外区, 吸 收峰(564 nm)相比 P7 (545 nm)红移 $20 \mathrm{~nm}$; (2)具有较高 的空穴载流子迁移能力. FET 测试所得 P8 薄膜的空穴载 流子迁移率为 $1 \times 10^{-3} \mathrm{~cm}^{2} \cdot \mathrm{V}^{-1} \cdot \mathrm{s}^{-1}$, 将近 $\mathbf{P 7}\left(3 \times 10^{-4}\right.$ $\left.\mathrm{cm}^{2} \cdot \mathrm{V}^{-1} \cdot \mathrm{s}^{-1}\right)$ 的十倍. 与 $\mathrm{CaO}$ 等的工作同时, Leclerc 等 ${ }^{[37]}$ 也报道了同样的共聚物 $\mathbf{P 8}\left(\mathrm{R}^{1}=\mathrm{R}^{2}=\right.$ octyl $)$, 但具有较 低分子量 $\left(M_{\mathrm{n}}=15000, M_{\mathrm{w}}=20000\right)$, 和 $\mathrm{PC}_{61} \mathrm{BM}$ 配合制 备的器件效率只为 $1.6 \%$. 最近, Leclerc 等 ${ }^{[38]}$ 又将芴基团 桥连 $\mathrm{C}$ 换成 $\mathrm{Ge}$, 得到共聚物 $\mathbf{P 9}\left(\mathrm{R}^{1}=\mathrm{R}^{2}=\right.$ octyl, $M_{\mathrm{n}}=$ 10000, PDI=2.4). P9 带隙为 $1.79 \mathrm{eV}$, 略小于 $\mathbf{P 7}$ 和 P8, 但和 $\mathrm{PC}_{61} \mathrm{BM}$ 配合制备的器件性能一般 $(\mathrm{PCE}=2.8 \%)$. 除了用 $\mathrm{C}$ 同族元素替代芴的桥连 $\mathrm{C}$ 之外, 还可用 $\mathrm{N}$ 代替 $\mathrm{C}$, 即用咔唑取代芴基团. 为此, 2007 年 Leclerc 研究小 组 ${ }^{[39]}$ 报道了共聚物 $\mathbf{P 1 0}\left(\mathrm{R}=9\right.$-heptadecanyl, $M_{\mathrm{n}}=$ $\left.37000, M_{\mathrm{w}}=73000\right) . P 10$ 薄膜表现出两个吸收谱带, 吸 收峰分别位于 398 和 $576 \mathrm{~nm}$, 带隙为 $1.88 \mathrm{eV}$, 并具有较 为理想的 HOMO 和 LUMO 能级(分别为 -5.5 和 -3.6 $\mathrm{eV}) . \mathbf{P 1 0}$ 和 $\mathrm{PC}_{61} \mathrm{BM}$ 混合制备的太阳能电池器件光电转 换效率为 $3.6 \%\left(V_{\mathrm{OC}}=0.89 \mathrm{~V}, J_{\mathrm{SC}}=6.92 \mathrm{~mA} \cdot \mathrm{cm}^{-2}, \mathrm{FF}=\right.$ $0.63)$, 和 $\mathrm{PC}_{71} \mathrm{BM}$ 配合制备的电池器件效率达到 $6.1 \%$ $\left(V_{\mathrm{OC}}=0.88 \mathrm{~V}, J_{\mathrm{SC}}=10.6 \mathrm{~mA} \cdot \mathrm{cm}^{-2}, \mathrm{FF}=0.66\right)^{[40]}$. $\mathrm{Zhu}$ 等 ${ }^{[41]}$ 利用桥连的二噻吩和苯并噻二唑共聚, 得 到共聚物 P11 $\left(M_{\mathrm{n}}=28000, \mathrm{PDI}=1.5\right)$. 聚合物在氯仿溶 液中吸收谱带位于 $721 \mathrm{~nm}$, 膜状态时红移至 $760 \mathrm{~nm}$, 带 隙为 $1.4 \mathrm{eV}$, 并具有较为理想的 HOMO 和 LUMO 能级 (分别为 -5.3 和 $-3.55 \mathrm{eV}$ ), FET 测试表明 P11 还具有较 高的载流子迁移率 $\left(2 \times 10^{-2} \mathrm{~cm}^{2} \cdot \mathrm{V}^{-1} \cdot \mathrm{s}^{-1}\right)$. 利用 P11 作

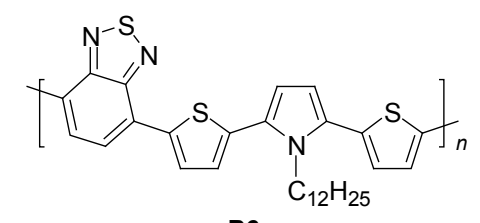

P6
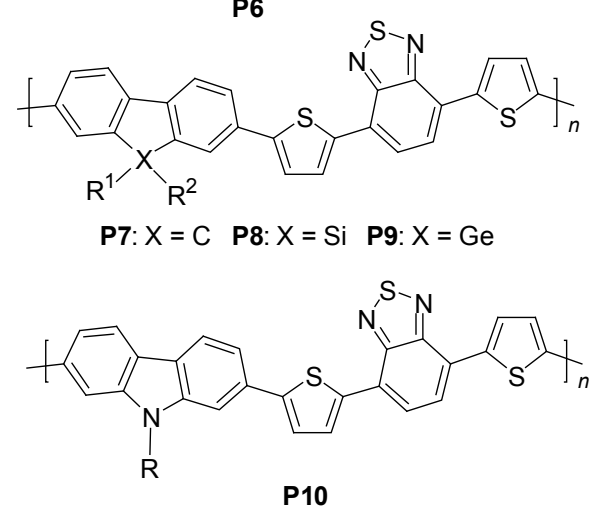

为电子给体和 $\mathrm{PC}_{61} \mathrm{BM}$ 配合制备电池器件, 得到的器件 效率为 $2.67 \%$, 而和 $\mathrm{PC}_{71} \mathrm{BM}$ 配合, 效率提高至 $3.16 \%{ }^{[42]}$. 活性层通过添加硫醇处理, 器件效率进一步 提高至 5.5\% ${ }^{[43]}$. 受 P8 比 P7 性能优越的启发, Yang 等 ${ }^{[44]}$ 用 $\mathrm{Si}$ 来桥连两噻吩, 之后和苯并噻二唑共聚得到聚合 物 P12 ( $\mathrm{R}=$ 2-ethylhexyl, $\left.M_{\mathrm{n}}=18000, \mathrm{PDI}=1.2\right) . \mathbf{P 1 2}$ 具 有和 $\mathbf{P 1 1}$ 相似的能隙 $\left(E_{\mathrm{g}}=1.45 \mathrm{eV}\right)$, 但具有较高的 HOMO 和 LUMO 能级 (分别为 -5.05 和 $-3.27 \mathrm{eV}$ ), 因 此和 $\mathrm{PC}_{70} \mathrm{BM}$ 配合制备的器件性能稍逊于 P11, 效率最 好为 $5.1 \%$. Bazan 等 ${ }^{[45]}$ 利用微波反应，得到不同分子量 的 P12 ( $\mathrm{R}=$ dodecanyl), 发现随着分子量从 7000 提高至 34000 , 和 $\mathrm{PC}_{71} \mathrm{BM}$ 制备的电池器件 $V_{\mathrm{OC}}$ 从 0.64 降至 0.57 $\mathrm{V}$, 但 $J_{\mathrm{SC}}$ 从 4.2 增至 $17.3 \mathrm{~mA} \cdot \mathrm{cm}^{-2}$, 而且. $\mathrm{FF}$ 也从 0.35 增至 0.61 , 结果导致器件的效率从 $1.2 \%$ 提高到 $5.9 \%$, 可 见分子量大小影响之大. Geng 和 Xie 等 ${ }^{[46]}$ 利用二噻吩并 吡咯基团和苯并噻二唑形成共聚物 P13, 合成了三种不 同烷基取代基(9-十七烷基、7-十三烷基和 6-十一烷基) 的版本, 最好的结果是 6-十一烷基，器件效率为 $2.8 \%$. 在聚合物 P10 和 P11 主链的单元结构中引入二噻吩基 团, 则形成了聚合物 $\mathbf{P 1 4} 4^{[47]}$ 和 $\mathbf{P 1 5} 5^{[48]}$, 但是性能反而有 所下降. 同样, P16 ${ }^{[49]}$ 和 P13 相比, 链节单元多两个噻吩 基团, 但性能类似.

一般, 共轭主链上各相邻芳环之间，由于位阻效应， 存在一定的二面角，而梯形结构则可强制将它们保持在 相同平面内, 从而提高它们之间的共轭程度. 为此, Katz 等 ${ }^{[50]}$ 设计并合成了共聚物 P17 和 P18. 相比 P7, P17 和 P18 单元链节有多个侧链, 由此带来较好的溶解性 能. 并且, P17 和 P18 吸收谱带比 P7 红移 16 19 nm, 但 P18 相对 P17 吸收光谱长波领域变化不大, 但 $400 \mathrm{~nm}$ 左 右的谱峰则有红移. 器件测试发现 P17 具有较高的载流 
子迁移率 $\left(0.011 \mathrm{~cm}^{2} \cdot \mathrm{V}^{-1} \cdot \mathrm{s}^{-1}\right)$, 而 $\mathbf{P} 18$ 则具有较高的光伏 性能. P18 与 $\mathrm{PC}_{61} \mathrm{BM}$ 以 $1: 4$ 比例混合制备的器件, 其 光电转化率为 $3.67 \%$, 而改用 $\mathrm{PC}_{71} \mathrm{BM}$, 器件效率提高至 $4.5 \%$. 类似的, $\mathrm{Lu}, \mathrm{Ding}$, Tao 等 ${ }^{[51]}$ 则利用吲哚并咔唑 (indolocarbazole)和噻吩、苯并噻二唑构筑共聚物 P19 $\left(\mathrm{R}^{1}=2\right.$-hexyldecyl, $\mathrm{R}^{2}=$ octyl, $\left.M_{\mathrm{n}}=19500, \mathrm{PDI}=2.08\right)$. 聚合物 P19 在 $\mathrm{CHCl}_{3}$ 溶液中光谱吸收峰位于 $538 \mathrm{~nm}$, 而 膜状态的吸收光谱则比此红移 $100 \mathrm{~nm}$, 表明聚合物链 与链间有较强的相互作用. 而且, 在 DSC 中观察到熔融 峰和结晶峰, 表明 P19 具有较高的结晶度. 虽然其带隙 $(1.89 \sim 2.02 \mathrm{eV})$ 并不理想, $\mathbf{P 1 9}$ 和 $\mathrm{PC}_{61} \mathrm{BM}$ 配合制备的器 件效率为 $3.6 \%\left(V_{\mathrm{OC}}=0.69 \mathrm{~V}, J_{\mathrm{SC}}=9.17 \mathrm{~mA} \cdot \mathrm{cm}^{-2}, \mathrm{FF}=\right.$
0.57). 接着, Hashimoto 研究小组 ${ }^{[52]}$ 同样合成了 P19 $\left(\mathrm{R}^{1}=1\right.$-decylundecyl, $\left.\mathrm{R}^{2}=\mathrm{H}\right)$ 和 $\mathbf{P 2 0}(\mathrm{R}=1$-decylundecyl $)$, 但效果不如前面的好. 较为引人注目的工作是 2010 年 Ting, Chen 等 $^{[53]}$ 的工作. 他们合成了 P21 $\left(M_{\mathrm{w}}=60900\right.$, $\mathrm{PDI}=2.51)$, 该聚合物光吸收谱峰位于 $570 \mathrm{~nm}$, 具有 $1.75 \mathrm{eV}$ 的带隙和较为理想的 HOMO 和 LUMO 能级(分 别为 -5.36 和 $-3.52 \mathrm{eV}$ ), 与 $\mathrm{PC}_{71} \mathrm{BM}$ 共混制备本体异质 结电池器件, 光电转换效率为 $5.56 \%$, 器件活性层经溶 剂蒸汽退火处理，效率提高至 $6.41 \%$.

Geng 等 ${ }^{[54]}$ 利用简单的寡聚噻吩和苯并噻二唑构筑 窄带隙聚合物，设计合成了 P22 至 P26 共聚物，其结构<smiles>[R][X]1([R])c2cc(C)sc2c2sc(C3=CC=C4CC5C4=NSN=C35)cc21</smiles>

P11: $X=C \quad$ P12: $X=S i$<smiles></smiles>

P13

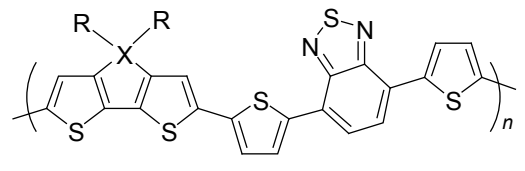

P14: $X=C \quad$ P15: $X=S i$<smiles></smiles><smiles>[R]C1([R])c2cc(C)ccc2-c2cc3c(cc21)-c1ccc(-c2ccc(-c4ccc(-c5ccc(C(C)(C)C)s5)c5nsnc45)s2)cc1C3([R])[R]</smiles>

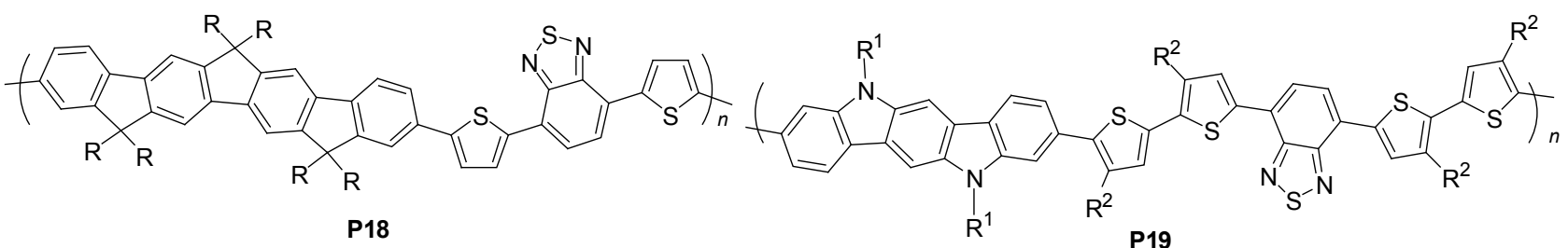<smiles>[R]n1c2cc(C)ccc2c2cc3c(cc21)c1ccc(-c2ccc(-c4ccc(-c5ccc(C)s5)c5nsnc45)s2)cc1n3[R]</smiles><smiles>[134IH]</smiles>

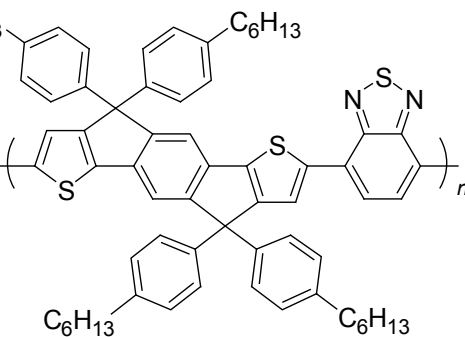

P21<smiles>CCCc1cc(C(C)(C)C)sc1-c1sc(-c2ccc(C)c3nsnc23)cc1CC</smiles>

P22

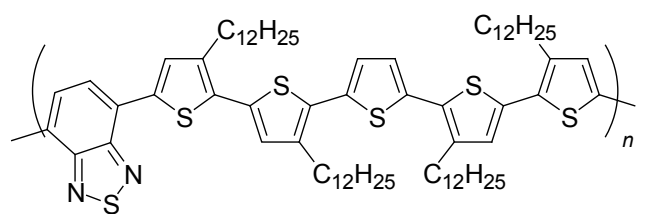

P25

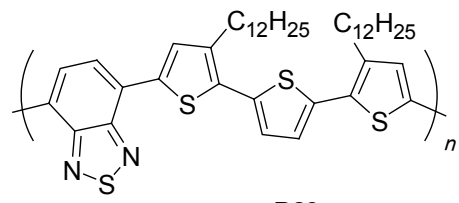

P23

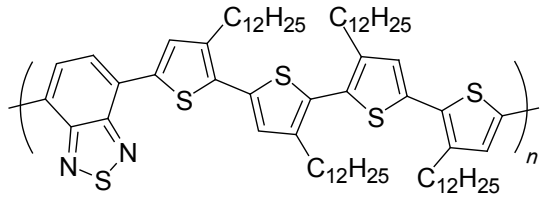

P24

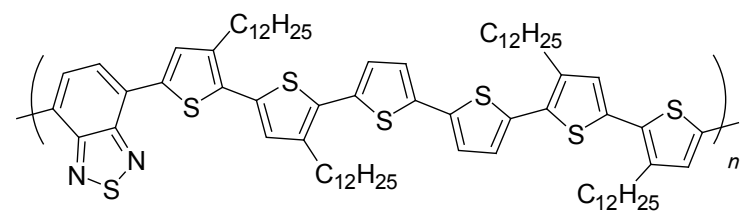

P26 
特征是单元链节分别含有 $2 \sim 6$ 个噻吩基团. 他们研究 发现, 材料的光谱、电化学、能级结构不但与单元链节 噻吩的个数有关, 还与噻吩上取代基的位置有关 (表

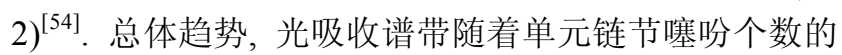
增加而红移, 带隙也随之降低. 但是, 当相邻噻吩上取 代基有位阻效应时, 吸收谱带会蓝移, 比如 P24 相比 P23, 表明其主链的相邻噻吩环的共平面性变差. 而且, 聚合物 P25 和 P26 的薄膜具有尖锐的 XRD 衍射峰, FET 测试表明热处理后的薄膜具有较强的载流子迁移率 (P25: 2.46 $\times 10^{-2} \mathrm{~cm}^{2} \cdot \mathrm{V}^{-1} \cdot \mathrm{s}^{-1}$, P26: $1.40 \times 10^{-2} \mathrm{~cm}^{2} \cdot \mathrm{V}^{-1}$. $\mathrm{s}^{-1}$ ). 这些聚合物和 $\mathrm{PC}_{61} \mathrm{BM}$ 配合制备本体异质结电池 器件, 最好的结果为单元链节含六个噻吩的 P26, 光电 转换效率为 $2.23 \%$ (表 2). Lu 和 Ding 等 ${ }^{[55]}$ 也合成了类似 的葟聚噻吩和苯并噻二唑的共聚物, 其中 P27 含有更多 的噻吩环, 但光伏性能一般. 最近, 此类聚合物引人瞩 目的工作是 Chen 等 ${ }^{[56]}$ 报道的 P28. 他们利用四聚噻吩 和苯并噻二唑构筑共聚物得到 P28, 重要的结构特征为 中间两个噻吩环上各有一互相背向的庞大的支化烷基 长链, 这样既解决了溶解度的问题, 又避免侧链引起的 位阻效应. 聚合物 P28 具有数均分子量 35000 , 带隙为 $1.59 \mathrm{eV}, \mathrm{HOMO}$ 为 $-5.18 \mathrm{eV}$. 更重要的是, P28 薄膜经过 $200{ }^{\circ} \mathrm{C}$ 处理 $30 \mathrm{~min}$ 后, FET 测试所得载流子迁移率高达 $0.13 \sim 0.20 \mathrm{~cm}^{2} \cdot \mathrm{V}^{-1} \cdot \mathrm{s}^{-1}$, 开关比为 $10^{6} \sim 10^{7}$. 此聚合物 和 $\mathrm{PC}_{71} \mathrm{BM} 1: 1$ 混合, 制备本体异质结电池器件, 获得
$6.26 \%$ 的光电转换效率 $\left(V_{\mathrm{OC}}=0.722 \mathrm{~V}, J_{\mathrm{SC}}=12.3 \mathrm{~mA}\right.$ $\mathrm{cm}^{-2}, \mathrm{FF}=0.705$ ).

从上述例子可以看出, 含苯并噻二唑的窄带隙聚合 物, 普遍的做法是在电子给体基团上引入侧链, 提高聚 合物的溶解度. 2009 年, Bo, Liu 和 Zhang 等 ${ }^{[57]}$ 改变这种 做法, 在苯并噻二唑 5,6 位引入烷氧基团, 设计并合成 了共聚物 P29. P29 $\left(M_{\mathrm{n}}=166000, \mathrm{PDI}=3.1\right)$ 具有光吸收 谱峰在 $579 \mathrm{~nm}$, 而带隙为 $1.95 \mathrm{eV}$, HOMO 和 LUMO 能 级分别为 -5.21 和 $-3.35 \mathrm{eV}$, 其和 $\mathrm{PC}_{71} \mathrm{BM}$ 配合制备的 电池光电转换效率为 $5.4 \%\left(V_{\mathrm{OC}}=0.81 \mathrm{~V}, J_{\mathrm{SC}}=9.8\right.$ $\mathrm{mA} \cdot \mathrm{cm}^{-2}, \mathrm{FF}=0.69$ ). 作者认为这么好的器件效率, 得 益于 $\mathbf{P 2 9}$ 具有比较均衡的载流子迁移能力 $\left(\mu_{\mathrm{e}} \approx 1 \times 10^{-4}\right.$ $\mathrm{cm}^{2} \cdot \mathrm{V}^{-1} \cdot \mathrm{s}^{-1}, \mu_{\mathrm{e}}=3 \times 10^{-4} \mathrm{~cm}^{2} \cdot \mathrm{V}^{-1} \cdot \mathrm{s}^{-1}$ ). 几乎同时, Helgesen 等 ${ }^{[58}$ 报道了共聚物 $\mathbf{P 3 0} \sim \mathbf{P 3 2}$, 也是基于 5,6 双取 代的苯并噻二唑, 但是性能一般. 表现最好的是 $\mathbf{P 3 0}$, 它和 $\mathrm{PC}_{61} \mathrm{BM}$ 配合, 获得较高的开路电压 $\left(V_{\mathrm{OC}}=0.93 \mathrm{~V}\right)$, 但闭路电流密度和填充因子一般 $\left(J_{\mathrm{SC}}=5.18 \mathrm{~mA} \cdot \mathrm{cm}^{-2}\right.$, $\mathrm{FF}=0.46$ ), 最终效率为 $2.22 \%$.

\section{2 基于芳基酰胺、酰亚胺基团}

芳酰亚胺衍生物, 比如荍酰亚胺(Perylene diimide, PDI)、荟酰亚胺(Naphthalene diimide, NDI)具有非常强的 接受电子能力, 常用作电子受体, 因此将这些基团引入 至共轭聚合物的主链, 和电子富有基团交替共聚, 有可 能得到性能优良的窄带隙聚合物. 为此, Zhan, Li, Zhu,

表 2 P22 P26 聚合物性质及其和 $\mathrm{PC}_{61} \mathrm{BM}$ 配合制备电池器件的性质

Table 2 Properties of $\mathbf{P 2 2} \sim \mathbf{P 2 6}$ and performance of organic solar cells fabricated together with $\mathrm{PC}_{61} \mathrm{BM}$

\begin{tabular}{|c|c|c|c|c|c|c|c|c|c|c|}
\hline \multirow{2}{*}{ Polymer } & \multicolumn{2}{|c|}{$\lambda_{\max } / \mathrm{nm}$} & \multirow{2}{*}{$\mathrm{HOMO} / \mathrm{eV}$} & \multirow{2}{*}{ LUMO/eV } & \multicolumn{2}{|c|}{$E_{\mathrm{g}} / \mathrm{eV}$} & \multirow{2}{*}{$V_{\mathrm{OC}} / \mathrm{V}$} & \multirow{2}{*}{$J_{\mathrm{SC}} /\left(\mathrm{mA} \cdot \mathrm{cm}^{-2}\right)$} & \multirow{2}{*}{$\mathrm{FF}$} & \multirow{2}{*}{$\mathrm{PCE} / \%$} \\
\hline & Solution & Film & & & $\mathrm{CV}$ & Opt. & & & & \\
\hline P22 & 520 & 543 & -5.59 & -3.23 & 2.36 & 1.97 & 1.18 & 3.53 & 0.30 & 1.23 \\
\hline P23 & 535 & 632 & -5.03 & -3.17 & 1.86 & 1.59 & 0.68 & 3.11 & 0.44 & 0.93 \\
\hline P24 & 536 & 577 & -5.20 & -3.18 & 2.02 & 1.72 & 1.22 & 3.75 & 0.36 & 1.62 \\
\hline P25 & 551 & 662 & -4.88 & -3.10 & 1.78 & 1.56 & 0.66 & 5.09 & 0.57 & 1.91 \\
\hline P26 & 536 & 657 & -4.94 & -3.18 & 1.76 & 1.52 & 0.85 & 5.62 & 0.47 & 2.23 \\
\hline
\end{tabular}

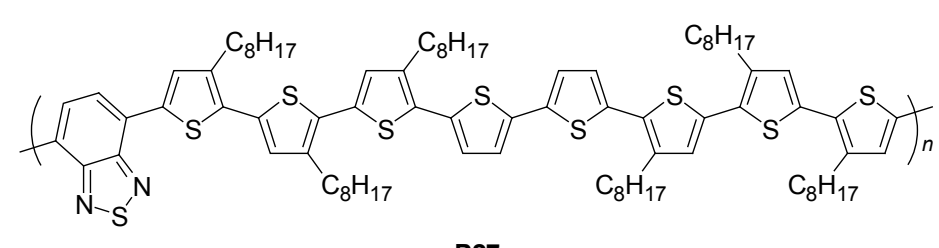

P27
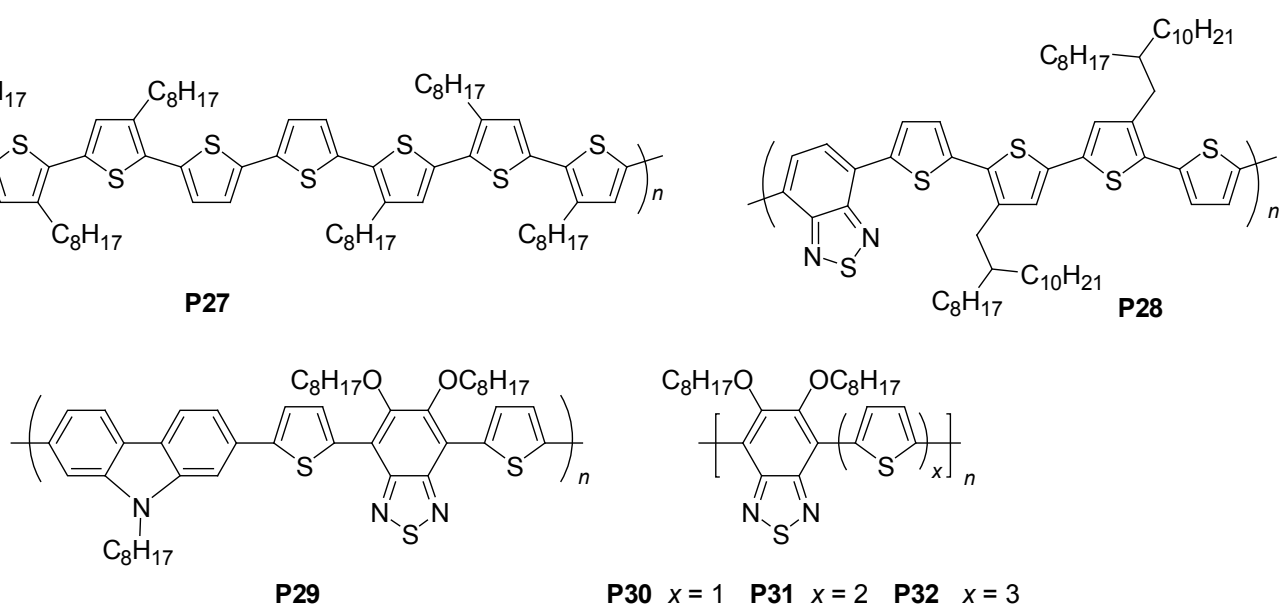
Kippelen, Marder 等 ${ }^{[59]}$ 将 PDI 和二噻吩并噻吩(Dithienothiophene, DTT)共聚得到聚合物 P33 $\left(M_{\mathrm{w}}=15000\right.$, $\mathrm{PDI}=1.5)$. 此聚合物吸收谱带延伸至 $850 \mathrm{~nm}$, 而电子 亲和势( $\mathrm{LUMO}$ 能级)为 $-3.9 \mathrm{eV}$, 可和 $\mathrm{PC}_{61} \mathrm{BM}$ 相比拟. 更重要是, FET 测试表明其聚合物是典型的 $\mathrm{n}$ 型材料, 具有较高的电子迁移能力 $\left(\mu_{\mathrm{e}}=1.3 \times 10^{-2} \mathrm{~cm}^{2} \cdot \mathrm{V}^{-1} \cdot \mathrm{s}^{-1}\right)$. P33 与前述的聚合物 P5 共混制备全聚合物型本体异质 结太阳能电池, 效率为 $1 \%\left(V_{\mathrm{OC}}=0.63 \mathrm{~V}, J_{\mathrm{SC}}=4.2\right.$ $\left.\mathrm{mA} \cdot \mathrm{cm}^{-2}, \mathrm{FF}=0.39\right)$, 是全聚合物型太阳电池中效率最 好的. 随后, 他们 ${ }^{[60]}$ 又继续深化这方面的研究, 设计合 成了聚合物 P34 $\left(M_{\mathrm{w}}=43000, \mathrm{PDI}=2.2\right)$ 和 P35 $\left(M_{\mathrm{w}}=\right.$ $27000, \mathrm{PDI}=1.8)$, 目的是通过改变单元链节中 DTT 的 个数, 调控聚合物的性能. 随着 DTT 基团数目的增加, 聚合物的光吸收谱带逐渐红移, 带隙逐步变小, P35 的 吸收延伸至 $900 \mathrm{~nm}$, 带隙降至 $1.4 \mathrm{eV}$. 同时, 随着 DTT 基团数目的增加, HOMO 能级逐渐提高, 但 LUMO 能级 保持和 $\mathrm{PCBM}$ 差不多, 几乎不变. 应用 $\mathbf{P 3 3} \sim \mathbf{P 3 5}$ 和 P5 的类似物(侧链多一噻吩乙烯撑单元)共混, 制备电池器 件, 其开路电压基本保持在 $0.67 \sim 0.69 \mathrm{~V}, \mathrm{FF}$ 也没有很 大区别 $(0.40 \sim 0.43)$, 但 $\mathbf{P 3 4}$ 给出最大的 $J_{\mathrm{SC}}(3.71 \mathrm{~mA} \cdot$ $\left.\mathrm{cm}^{-2}\right)$, 因此效率最高 $(\mathrm{PCE}=1.08 \%)$. 同时, 他们还报道 了 P36, 用二噻吩并吡咯(Dithienopyrrole, DTP)替代 DTT. 相比 P34 至 P35, P36 在 600 900 nm 间具有更强 的吸收, 但和上述同样的聚合物给体材料配合, 得到的 电池器件性能一般. 2008 年, Hou, Yang 等 ${ }^{[61]}$ 将环戊并二 噻吩(cyclopenta[2,1- $b: 3,4-b]$ dithiophene, CPDT)和 PDI 配 合构筑交替共聚物 P37. 聚合物 P37 具有较低的 LUMO 能级 $(-4.02 \mathrm{eV})$, 也是典型的 $\mathrm{n}$ 型半导体材料. 比较有 意思的是, $P 37$ 可以多次重复进行 $p$ 和 $n$ 掺杂, 整个过程 是可逆的. 但是, P37 和 P12 配合制备的全聚合物型本 体异质结电池性能不佳. 去年, Shi, Chen 等 ${ }^{[62]}$ 报道了聚
合物 P38, 是 PDI 和二噻吩并苯 (dithienobenzene, DTB) 的交替共聚物. 同时，他们还报道了基于菜酰亚胺的共 聚物 P40 和苯酰亚胺的类似聚合物. 电化学测试表明 $\mathbf{P 3 8}$ 的 LUMO 能级为 $-4.18 \mathrm{eV}$, 而 $\mathbf{P 4 0}$ 的 LUMO 为一 $3.99 \mathrm{eV}$, 是典型的 $\mathrm{n}$ 型材料, 而基于苯酰亚胺的聚合物 则是 $\mathrm{p}$ 型材料. 最近, Xiao 等 ${ }^{[63]}$ 通过光环化反应 (Photocyclization), 以 PDI 与噻吩并噻吩的交替共聚物 为前体, 制备得到聚合物 P39. P39 是一种平面结构的聚 合物, 共轭特性强, 接受电子的能力强, 具有和 PCBM 差不多的 LUMO 能级 $(-3.98 \mathrm{eV})$, 是一种潜在的优秀受 体材料. 类似于菲酰亚胺, 䒬酰亚胺也具有非常强的电 子接受能力. 除了 $\mathrm{P40}$ 之外, P41 P44 ${ }^{[64]}$ 是基于 $\mathrm{NDI}$ 分 别和噻吩、二噻吩、芴的 D-A 交替聚合物, 都是 $\mathrm{n}$ 型半 导体材料. 其中, 比较有意思的是 P44, NDI 上修饰基团 为全氟碳链. 相比 P43, P44 拥有更长的吸收光谱和更小 的带隙. 作者认为全氟碳链的取代, 有利于主链的共平 面性.

最近，一些新的电子受体基团倍受关注. Diketopyrrolopyrrole (DPP)是其中之一, 它具有内酰胺的结 构, 使得芳环更加容易接受电子, 并在可见区具有较强 的吸收谱带. 2008 年, Winnewisser 等 ${ }^{[65]}$ 报道基于 DPP 基 团的窄带隙聚合物 P45 $\left(\mathrm{R}^{1}=\right.$ 2-hexyldecyl, $\mathrm{R}^{2}=$ dodecyl $)$, 并发现其具有优秀且均衡的双极性载流子迁移能力. 几 乎同时, Janssen 等 ${ }^{[66]}$ 报道了相同的聚合物 P45 $\left(M_{\mathrm{n}}=20\right.$ $000, \mathrm{PDI}=3.35$ ), 但 $\mathrm{R}^{1}$ 为 2-ethylhexyl. $\mathbf{P 4 5}$ 具有较低的 带隙, 为 $1.4 \mathrm{eV}$, 膜状态的光吸收拓展至 $860 \mathrm{~nm}$, 和 $\mathrm{PC}_{61} \mathrm{BM}$ 配合制备的电池器件效率为 $3.2 \%$, 改用 $\mathrm{PC}_{71} \mathrm{BM}$ 时效率提升至 $4 \%$. 之后, Janssen 等减少主链单 元含噻吩的数目, 重新合成得到聚合物 $\mathbf{P 4 6}{ }^{[67]}$ 和 $\mathbf{P 4} 7^{[68]}$. 其中, 性能较好的为 P47 $\left(\mathrm{R}=2\right.$-hexyldecyl, $M_{\mathrm{n}}=54000$, $\mathrm{PDI}=3.15)$, 其光吸收范围拓展至 $900 \mathrm{~nm}$, 并拥有较窄

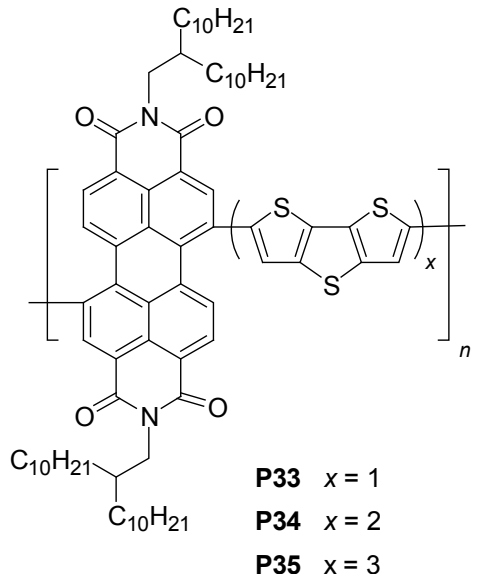

P35 $x=3$

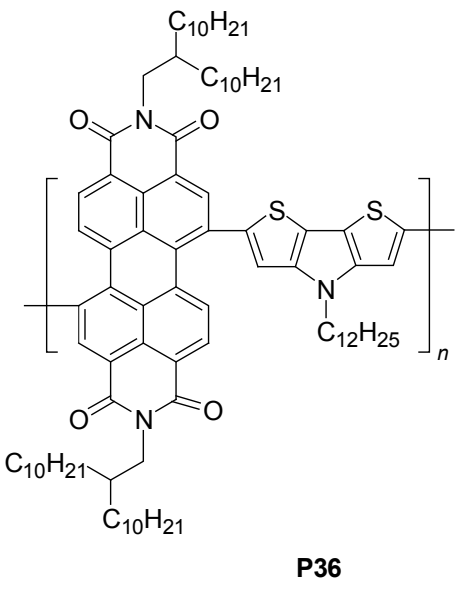

P36

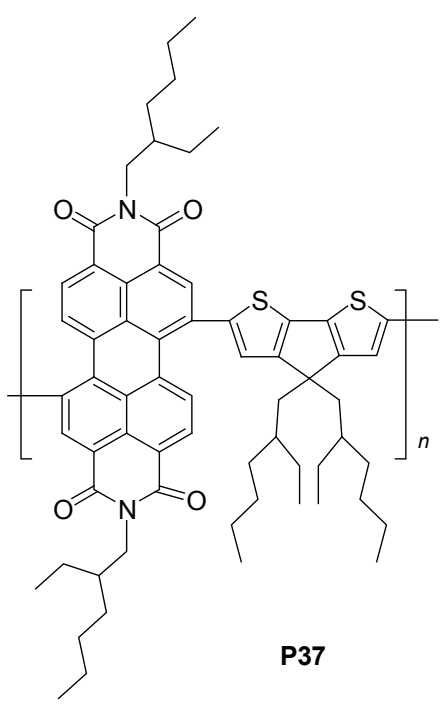

Chin. J. Org. Chem. 2012, 32, 266 283 

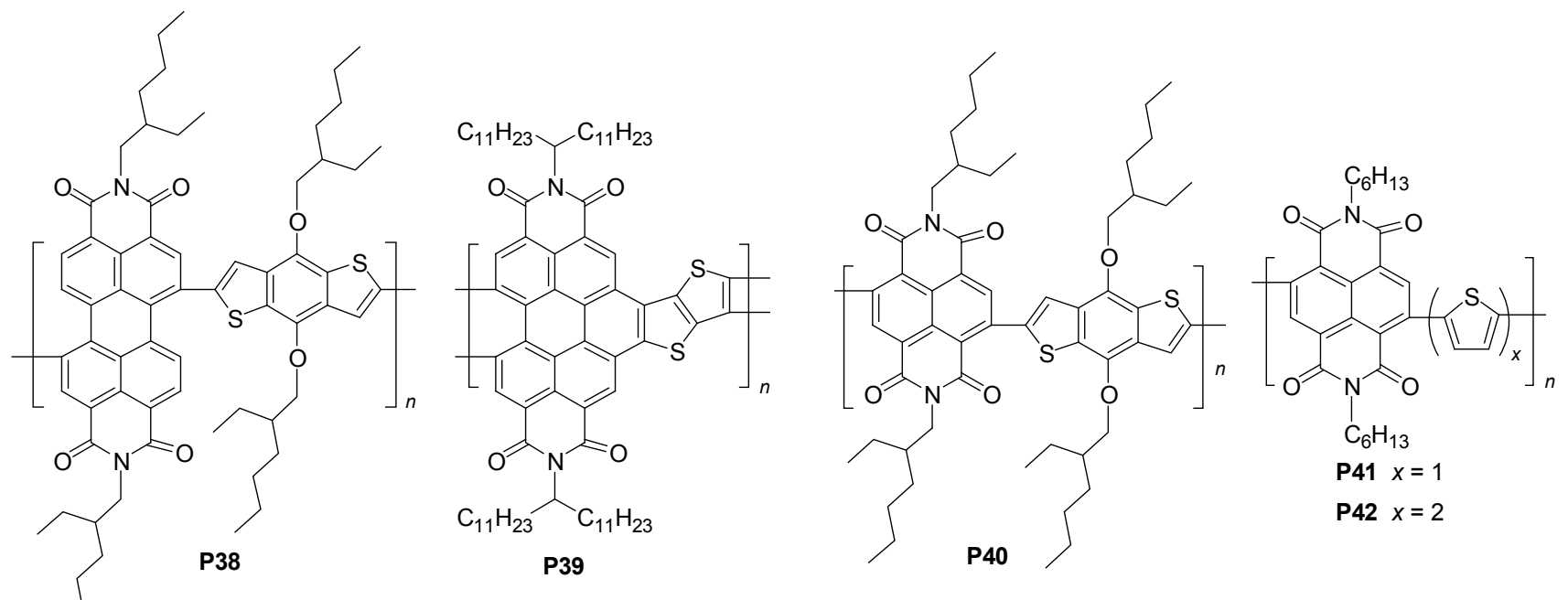

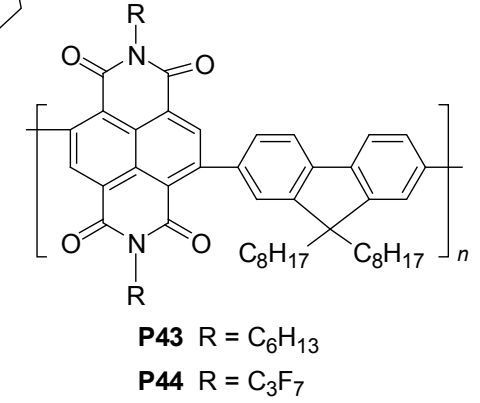

的带隙 $(1.30 \mathrm{eV})$, 更重要的是, FET 测试表明 P47 具有 均衡的双极性载流子迁移能力 $\left(\mu_{\mathrm{h}}=0.04 \mathrm{~cm}^{2} \cdot \mathrm{V}^{-1} \cdot \mathrm{s}^{-1}\right.$, $\left.\mu_{\mathrm{e}}=0.01 \mathrm{~cm}^{2} \cdot \mathrm{V}^{-1} \cdot \mathrm{s}^{-1}\right)$. 利用 $\mathbf{P} 47$ 和 $\mathrm{PC}_{61} \mathrm{BM}$ 共混体系制 备电池器件, 光电转换效率为 $3.8 \%\left(V_{\mathrm{OC}}=0.68 \mathrm{~V}, J_{\mathrm{SC}}=\right.$ $\left.8.3 \mathrm{~mA} \cdot \mathrm{cm}^{-2}, \mathrm{FF}=0.67\right)$, 改用 $\mathrm{PC}_{71} \mathrm{BM}$ 作为受体材料时, 器件效率提高至 $4.7 \%\left(V_{\mathrm{OC}}=0.65 \mathrm{~V}, J_{\mathrm{SC}}=11.8 \mathrm{~mA} \cdot \mathrm{cm}^{-2}\right.$, $\mathrm{FF}=0.6)$. 与 $\mathbf{P 4 6}$ 同时, Janssen 研究小组 ${ }^{[67]}$ 还报道了 $\mathbf{P 4 8}$ 和 P49, 是 DPP、噻吩分别同芴和 CPDT 交替共聚物. 相 比 $\mathbf{P 4 8}\left(\mathrm{R}^{1}=2\right.$-ethylhexy, $\mathrm{R}^{2}=$ octyl, $M_{\mathrm{w}}=17000, \mathrm{PDI}=$ 2.2), P49 ( ${ }^{1}=2$-ethylhexy, $\mathrm{R}^{2}=$ octyl, $M_{\mathrm{w}}=12000$, $\mathrm{PDI}=1.8)$ 具有更窄的带隙 $\left(\mathbf{P} 49: E_{\mathrm{g}}=1.39 \mathrm{eV} ; \mathbf{P 4 8}: E_{\mathrm{g}}=\right.$

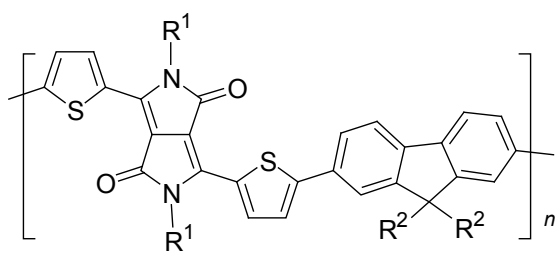

P48

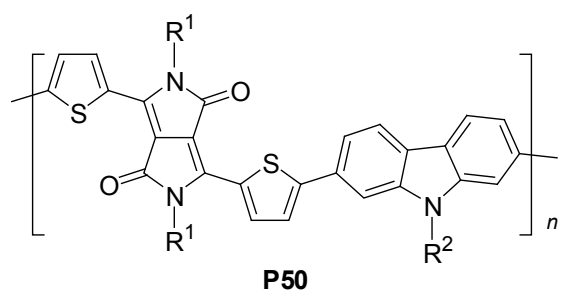

$1.77 \mathrm{eV})$, 吸收拓展至 $950 \mathrm{~nm}$. 更重要的是, P49 具有更 高的空穴载流子迁移率 $\left(\mathbf{P 4 9}: \mu_{\mathrm{h}}=2.1 \times 10^{-3} \mathrm{~cm}^{2} \cdot \mathrm{V}^{-1}\right.$ ・ $\mathrm{s}^{-1} ;$ P48: $\left.\mu_{\mathrm{h}}=4.2 \times 10^{-6} \mathrm{~cm}^{2} \cdot \mathrm{V}^{-1} \cdot \mathrm{s}^{-1}\right)$, 因此导致 P49 和 $\mathrm{PC}_{61} \mathrm{BM}$ 配合制备的电池器件性能优于 $\mathbf{P 4 8}$ (P49: $\mathrm{PCE}=1.7 \%$; P48: $\mathrm{PCE}=0.9 \%)$. 几乎同时, Wei 等 ${ }^{[69]}$ 也 报道了聚合物 $\mathbf{P 4 9}\left(\mathrm{R}^{1}=\right.$ 2-ethylhexy, $\mathrm{R}^{2}=$ octyl $)$, 但分子 量更高 $\left(M_{\mathrm{w}}=38160, \mathrm{PDI}=2.12\right) . \mathbf{P 4 9}$ 与 $\mathrm{PC}_{71} \mathrm{BM}$ 以 $1: 3$ 的比例混合得到的本体异质结电池, 开路电压 $V_{\mathrm{OC}}=$ $0.47 \mathrm{~V}$, 填充因子 $\mathrm{FF}=0.45$, 短路电流 $J_{\mathrm{SC}}=10.87$ $\mathrm{mA} \cdot \mathrm{cm}^{-2}$, 光电转换效率 $\mathrm{PCE}=2.27 \%$. 将 $\mathbf{P 4 8}$ 和 $\mathbf{P} 49$ 的桥连 $\mathrm{C}$ 换成 $\mathrm{N}$, 则成为聚合物 P50 和 P51. Leclerc

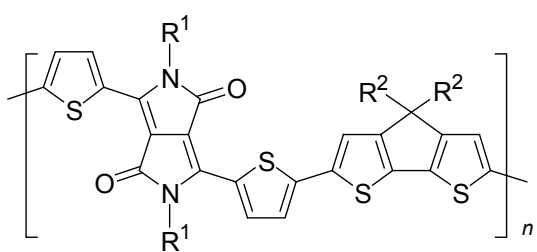

P49

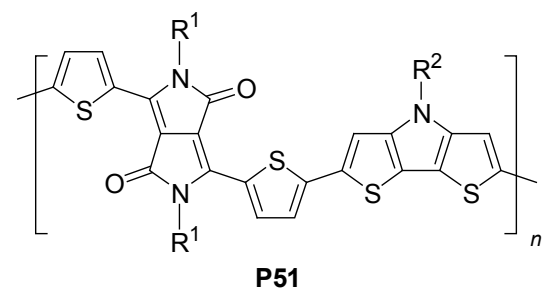


等 ${ }^{[70]}$ 报道了 P50 $\left(\mathrm{R}^{1}=\right.$ octyl, $\mathrm{R}^{2}=$ 9-heptadecyl, $M_{\mathrm{n}}=$ $30000, \mathrm{PDI}=2.1$ ), 其吸收峰位于 $680 \mathrm{~nm}$, 带隙为 1.57 $\mathrm{eV}, \mathrm{HOMO}$ 和 LUMO 分别为 $-5.44,-3.92 \mathrm{eV}$, 并具有 较高的空穴载流子迁移率 $\left(\mu_{\mathrm{h}}=0.02 \mathrm{~cm}^{2} \cdot \mathrm{V}^{-1} \cdot \mathrm{s}^{-1}\right)$. P50 和 $\mathrm{PC}_{61} \mathrm{BM}$ 以 $1: 2$ 混合制备电池器件, 测得效率为 $1.6 \%$ $\left(V_{\mathrm{OC}}=0.85 \mathrm{~V}, J_{\mathrm{SC}}=5.2 \mathrm{~mA} \cdot \mathrm{cm}^{-2}, \mathrm{FF}=0.37\right)$. Hashimoto 等 ${ }^{[71]}$ 则报道了 P51 $\left(\mathrm{R}^{1}=\right.$ octyl, $\mathrm{R}^{2}=$ 9-heptadecyl, $M_{\mathrm{n}}=$ $18900, \mathrm{PDI}=2.04)$. P51 具有从 500 至 $1100 \mathrm{~nm}$ 非常宽广 的吸收光谱, 半峰宽高达 $324 \mathrm{~nm}$, 电化学测得其 HOMO 和 LUMO 能级位于 -4.90 和 $-3.63 \mathrm{eV}$, 给出带 隙为 $1.27 \mathrm{eV}$. 而且, P51 薄膜有较强的 XRD 衍射峰, 表 明具有一定的晶态结构, FET 测试得到其空穴载流子迁 移率为 $0.05 \mathrm{~cm}^{2} \cdot \mathrm{V}^{-1} \cdot \mathrm{s}^{-1}$. 利用 $\mathbf{P 5 1}$ 和 $\mathrm{PC}_{61} \mathrm{BM}$ 配合制备 本体异质结太阳能电池, 具有较高的电流密度(11.31 $\left.\mathrm{mA} \cdot \mathrm{cm}^{-2}\right)$, 但开路电压较低 $\left(V_{\mathrm{OC}}=0.40 \mathrm{~V}\right), \mathrm{FF}$ 值中等 $(0.52)$, 最终给出能量转换效率为 $2.34 \%$. 利用 $\mathrm{PC}_{71} \mathrm{BM}$ 作为电子给体材料, 效率略有提升, 为 $2.71 \%$. 而 Sharma 和 Patil 等 ${ }^{[72]}$ 则利用 DPP 和二噻吩并苯 (benzo[1,2-b;3,4-b]dithiophene, BDT) 构筑了聚合物 P52 $\left(\mathrm{R}^{1}=\mathrm{R}^{2}=\right.$ 2-hexyldecyl, $\left.M_{\mathrm{n}}=11560, \mathrm{PDI}=1.64\right) . \mathrm{P} 52$ 膜 具有从紫外至 $866 \mathrm{~nm}$ 比较宽广的吸收谱带, 峰值位于 $656 \mathrm{~nm}$, 而带隙宽度为 $1.43 \mathrm{eV}, \mathrm{HOMO}$ 和 LUMO 能级 分别位于 $-5.15,-3.69 \mathrm{eV}$. 利用 $\mathbf{P 5 2}$ 和 $\mathrm{PC}_{61} \mathrm{BM}$ 的共 混体系, 制备电池器件, 效率为 $2.78 \%\left(V_{\mathrm{OC}}=0.74 \mathrm{~V}\right.$, $J_{\mathrm{SC}}=6.72 \mathrm{~mA} \cdot \mathrm{cm}^{-2}, \mathrm{FF}=0.56$ ).

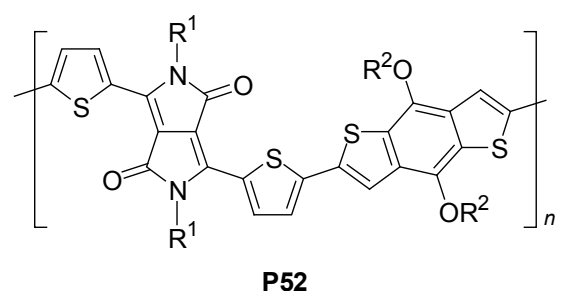

从上面例子可以看出, 大多数窄带隙共轭聚合物主 链是基于噻吩及其衍生物的. 但是, Fréchet 等 ${ }^{[73]}$ 则尝试 利用噻吩的类似物呋喃结合进共轭主链, 合成了聚合物 P53 ( $\mathrm{R}=2$-ethylhexyl, $\left.M_{\mathrm{n}}=66000\right)$ 和 P54 (R=2-ethylhexyl, $M_{\mathrm{n}}=29000$ ). 他们发现, 当侧链同为 2-乙基己基 时, 同时含呋喃、噻吩和 DPP 基团的聚合物 P53 具有较 好的溶解性能, 只含呋喃和 DPP 的 P54 次之, 而只含噻 吩和 DPP 的聚合物 P47 最差. P53 和 P54 都具有较为宽 广的吸收谱带, 从 $500 \mathrm{~nm}$ 延伸至约 $900 \mathrm{~nm}$, 从起始吸 收波长得到 $\mathbf{P 5 3}$ 带隙为 $1.41 \mathrm{eV}$, 而 $\mathbf{P 5 4}$ 带隙为 $1.35 \mathrm{eV}$. 电化学研究发现这两种聚合物都具有较低的 HOMO 能 级, P53 的为 $-5.4 \mathrm{eV}$, 而 P54 的为 $-5.5 \mathrm{eV}$, 这非常有 利于和 PCBM 配合时得到高的 $V_{\mathrm{OC}}$. 利用 $\mathbf{P 5 3}$ 和 $\mathbf{P 5 4}$ 与
$\mathrm{PC}_{61} \mathrm{BM}$ 配合制备本体异质结电池器件, 得到能量转换 效率分别为 $3.4 \%$ 和 $3 \%$, 差别不大. 当活性层旋涂时, 在旋涂溶液(氯苯)中加入体积分数为 $1 \%$ 的 1 -氯萘, 器 件效率稍微有所提升. 比较有意思的是, 当用 $\mathrm{PC}_{71} \mathrm{BM}$ 作为电子受体时, 旋涂时 1-氯荎的添加非常关键. 比如, $P 53$ 与 $\mathrm{PC}_{71} \mathrm{BM}$ 以 $1: 3$ 共混时, 旋涂溶液未加 1 -氯荎制 的器件效率只有 $0.86 \%$, 加入 $9 \%$ 的 1-氯荎器件效率提 高到 $5 \%\left(V_{\mathrm{OC}}=0.74 \mathrm{~V}, J_{\mathrm{SC}}=11.2 \mathrm{~mA} \cdot \mathrm{cm}^{-2}, \mathrm{FF}=0.6\right)$. 同样的, P54 和 $\mathrm{PC}_{71} \mathrm{BM}$ 配合时, 旋涂溶液添加 1-氯菱, 可以使器件效率从不到 $1 \%$ 提高到平均 $3.8 \%$.

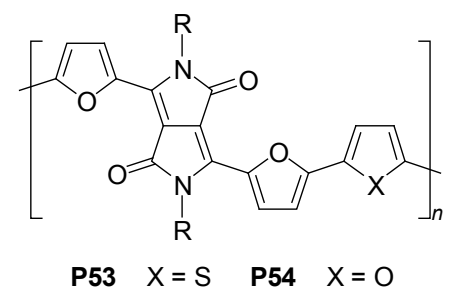

除了 DPP, thieno[3,4-c]pyrrole-4,6-dione (TPD)也是 最近令人瞩目的电子受体基团. 2010 年，几乎同时有 4 篇论文报道了 TPD 和二噻吩并苯 BDT 的交替共聚物 P55. 最早投稿的是 Leclerc 等 ${ }^{[74]}$, 他们采用 $R^{1}$ 为直链的 octyl, $\mathrm{R}^{2}$ 为支链的 2-ethylhexyl, 得到 P55 $\left(M_{\mathrm{n}}=13000\right.$, $\left.M_{\mathrm{w}}=34000\right)$. 性能研究表明 $\mathbf{P 5 5}$ 带隙较宽, 为 $1.8 \mathrm{eV}$, 但具有非常低的 HOMO 能级, 为 $-5.56 \mathrm{eV}, \mathrm{LUMO}$ 位于 $-3.75 \mathrm{eV}$. 应用 $\mathbf{P 5 5}$ 和 $\mathrm{PC}_{71} \mathrm{BM}$ 制备电池器件, 能量转 换效率为 $5.5 \%\left(V_{\mathrm{OC}}=0.85 \mathrm{~V}, J_{\mathrm{SC}}=9.81 \mathrm{~mA} \cdot \mathrm{cm}^{-2}, \mathrm{FF}=\right.$ 0.66). Jen 等 ${ }^{[75]}$ 报道了完全一样但分子量更高的聚合物 P55 $\left(M_{\mathrm{n}}=33000, \mathrm{PDI}=2.3\right)$, 和 $\mathrm{PC}_{71} \mathrm{BM}$ 制备的电池器 件能量转换效率为 $3.2 \% \sim 4.2 \%$. 而 Zhang 和 Xie 等 ${ }^{[76]}$ 报道的 $\mathbf{P 5 5}, \mathrm{R}^{1}$ 采用长支链烷烃(2-辛基十二烷基), $\mathrm{R}^{2}$ 则 有两个版本，一为十二烷基，另一为 2-乙基己基，得到 的两种 P55 的分子量都比较高, $M_{\mathrm{n}}$ 分别为 43500 和 91100. 他们发现所得到的 P55 和 $\mathrm{PC}_{71} \mathrm{BM}$ 配合制备电池 时, 需要添加 1,8-二磑辛烷, 电池效率才能提高至 $4.79 \%$. Fréchet 研究小组 ${ }^{[77]}$ 则详细研究了 TPD 侧链的影 响. 他们固定 $\mathrm{R}^{2}$ 为 2-乙基已基, $\mathrm{R}^{1}$ 则选择 2-乙基已基、 3,7-二甲基辛基和正辛基，得到的聚合物分子量相当， 分别为 42000, 39000 和 35000. 性能研究表明选择较长 的烷基链时, 吸收光谱有所红移, 表明共轭主链更加平 面化. 除此之外, 其他性质大致一样. 但引人瞩目的是, 这些具有不同侧链的 $\mathbf{P 5 5}$ 和 $\mathrm{PC}_{61} \mathrm{BM}$ 配合制备本体异质 结电池器件, 所得的器件性能相差很大. 当 $\mathrm{R}^{1}$ 为 2 -乙基 己基时, 优化后的器件效率为 3.9\%, $\mathrm{R}^{1}$ 改用 3,7-二甲基 辛基时，器件效率提高至 5.4\%, 而 $\mathrm{R}^{1}$ 为辛基时，效率最 高, 达到 6.6\%. 进一步研究表明, 当侧链从 2-乙基已基 
变为 3,7-二甲基辛基再到正辛基时, 聚合物链间距离变 小, 有利于 $\pi-\pi$ 相互作用. 同年, Wei 等 ${ }^{[78]}$ 报道了聚合物 P56 $\left(\mathrm{R}^{1}=2\right.$-hexyldecyl, $\mathrm{R}^{2}=$ dodecyl, $M_{\mathrm{n}}=9700, \mathrm{PDI}=$ 1.4). 聚合物 $\mathbf{P 5 6}$ 具有能隙为 $1.82 \mathrm{eV}, \mathrm{HOMO}$ 和 LUMO 能级位于 -5.56 和 $-3.10 \mathrm{eV} . \mathbf{P 5 6}$ 在薄膜状态具有强的 链间相互作用, 表现在其吸收谱带 $(572 \mathrm{~nm})$ 比溶液状态 红移 $104 \mathrm{~nm}$, 并具有多级较强的 XRD 衍射峰, 应用 SCLC 法(Space-charge-limited current method)测试所得 其空穴迁移率为 $1 \times 10^{-4} \mathrm{~cm}^{2} \cdot \mathrm{V}^{-1} \cdot \mathrm{s}^{-1}$, 和 $\mathrm{PC}_{61} \mathrm{BM}$ 共混 后膜的空穴迁移率为 $8 \times 10^{-5} \mathrm{~cm}^{2} \cdot \mathrm{V}^{-1} \cdot \mathrm{s}^{-1}$. 基于 $\mathbf{P 5 6}$ 和 $\mathrm{PC}_{61} \mathrm{BM}$ 混合体系的电池器件, 优化后的器件效率为 $4.7 \%\left(V_{\mathrm{OC}}=0.95 \mathrm{~V}, J_{\mathrm{SC}}=8.02 \mathrm{~mA} \cdot \mathrm{cm}^{-2}, \mathrm{FF}=0.62\right) .2011$ 年, Jenekhe 和 Watson 等 ${ }^{[79]}$ 则合成了聚合物 P57 $\left(\mathrm{R}^{1}=\right.$ dodecyl, $\mathrm{R}^{2}=$ octyl, $\left.M_{\mathrm{n}}=64000, \mathrm{PDI}=4.7\right) . \mathrm{P57}$ 膜的吸收 谱峰位于 $688 \mathrm{~nm}$, 带隙为 $1.67 \mathrm{eV}$, 测得 HOMO 和 LUMO 能级分别为 -5.26 和 $-3.59 \mathrm{eV}$. FET 测试表明 P57 膜具有一定的空穴载流子迁移能力 $\left[\mu_{\mathrm{h}}=7.8 \times\right.$ $10^{-3} \sim 8.4 \times 10^{-3} \mathrm{~cm}^{2} \cdot \mathrm{V}^{-1} \cdot \mathrm{s}^{-1}$ ]. 应用 $\mathbf{P 5 7}$ 和 $\mathrm{PC}_{71} \mathrm{BM}$ 配合 制备的最优器件, 能量转换效率为 $3.06 \%\left(V_{\mathrm{OC}}=0.76 \mathrm{~V}\right.$, $\left.J_{\mathrm{SC}}=8.12 \mathrm{~mA} \cdot \mathrm{cm}^{-2}, \mathrm{FF}=0.50\right)$. 之后, $\mathrm{Lu}$, Leclerc 和 Tao 等 ${ }^{[80]}$ 报道 $\mathbf{P 5 8}\left(\mathrm{R}^{1}=\right.$ octyl, $\mathrm{R}^{2}=2$-ethylhexyl, $M_{\mathrm{n}}=28000$, $\mathrm{PDI}=1.6)$, 是一种很好的材料. 聚合物 P58 膜具有从紫 外至 $717 \mathrm{~nm}$ 的宽广吸收谱带, 对应能隙为 $1.73 \mathrm{eV}$. 电 化学测试得到其 HOMO 和 LUMO 能级分别位于 -5.57 和 $-3.88 \mathrm{eV}$. 基于 $\mathbf{P 5 8}$ 与 $\mathrm{PC}_{71} \mathrm{BM}$ 共混的电池, 优化后 器件效率高达 $7.3 \%\left(V_{\mathrm{OC}}=0.88 \mathrm{~V}, J_{\mathrm{SC}}=12.2 \mathrm{~mA} \cdot \mathrm{cm}^{-2}\right.$, $\mathrm{FF}=0.68)$. 这是目前报道的有机太阳能电池效率最高 的器件之一. 而且, 他们还发现, 在活性层旋涂过程中, 旋涂液添加 1,8-二碘辛烷非常关键. 若不加, 器件效率 不到 $1 \%$.

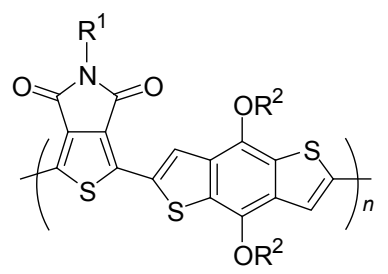

P55

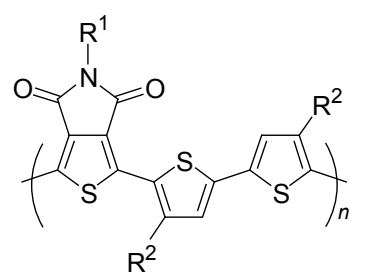

P56

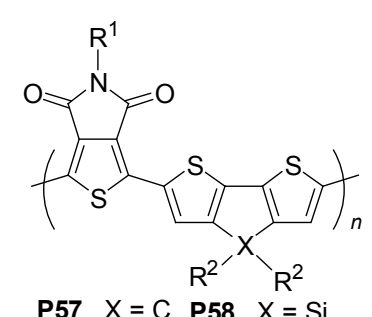

最近 Xie 和 Zhang 等 ${ }^{[81]}$ 报道了聚合物 $\mathbf{P 5 9}$, 是基于 一种新的内酰胺受体基团 Isoindigo (ID)的窄带隙聚合
物. P59 $\left(\mathrm{R}^{1}=\mathrm{R}^{2}=\right.$ 2-ethylhexyl, $\left.M_{\mathrm{n}}=219000, \mathrm{PDI}=1.5\right)$ 在膜状态的吸收谱带位于 $688 \mathrm{~nm}$, 并具有起始点为 803 $\mathrm{nm}$, 相对应于 $1.54 \mathrm{eV}$ 带隙, 电化学测试得到其 HOMO 和 LUMO 能级分别位于 -5.20 和 $-3.66 \mathrm{eV}$. 利用 $\mathbf{P 5 9}$ 和 $\mathrm{PC}_{71} \mathrm{BM}$ 制备太阳电池, 优化后器件性能为 $\mathrm{PCE}=$ $1.91 \%, V_{\mathrm{OC}}=0.71 \mathrm{~V}, J_{\mathrm{SC}}=7.93 \mathrm{~mA} \cdot \mathrm{cm}^{-2}, \mathrm{FF}=0.34$. 器 件效率一般, 主要原因是其活性层空穴迁移率不高, 只 有 $1.07 \times 10^{-5} \mathrm{~cm}^{2} \cdot \mathrm{V}^{-1} \cdot \mathrm{s}^{-1}$.

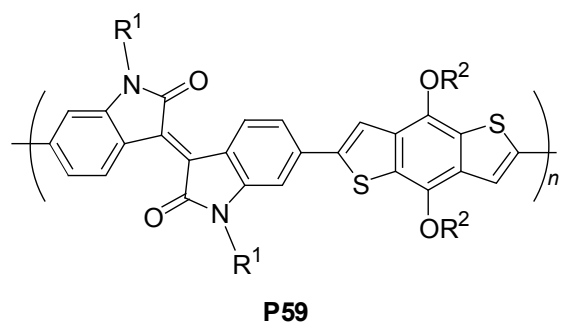

\section{3 氮杂芳环基团}

氮杂芳环, 比如喹喔啉 (Quinoxaline, QO), 是一类 常见的缺电子基团, 常被当作电子受体基团用于构筑各 种窄带隙聚合物. 比如, 2009 年 Chen 等 ${ }^{[82]}$ 合成了聚合 物 $\mathbf{P 6 0}\left(M_{\mathrm{w}}=10680, \mathrm{PDI}=1.74\right)$, 是吲哚并咔唑 (indolocarbazole)和 QO 的交替共聚物, 但其带隙并不窄, 为 $2.31 \mathrm{eV}$. 而且, $\mathbf{P 6 0}$ 的 $\mathrm{HOMO}$ 能级为 $-5.12 \mathrm{eV}$, 略显 高些. 当 $\mathrm{P60}$ 和 $\mathrm{PC}_{61} \mathrm{BM}$ 配合制备本体异质结电池时, 优化后最好效率只有 $0.87 \%\left(V_{\mathrm{OC}}=0.66 \mathrm{~V}, J_{\mathrm{SC}}=3.15\right.$ $\left.\mathrm{mA} \cdot \mathrm{cm}^{-2}, \mathrm{FF}=0.42\right)$, 而和 $\mathrm{PC}_{71} \mathrm{BM}$ 配合时, 效率提高至 $1.4 \%\left(V_{\mathrm{OC}}=0.65 \mathrm{~V}, J_{\mathrm{SC}}=4.46 \mathrm{~mA} \cdot \mathrm{cm}^{-2}, \mathrm{FF}=0.48\right) .2010$ 年 Hashimoto 等 ${ }^{[83}$ 报道了一系列基于 $\mathrm{QO}$ 的窄带隙聚合 物, 其中 P61 的性能最好. P61 膜状态在 $528 \mathrm{~nm}$ 处有最 大吸收, 起始吸收点为 $625 \mathrm{~nm}$, 对应光学能隙为 1.98 $\mathrm{eV}$, 电化学测得其 HOMO 和 LUMO 能级分别位于一 5.49 和 $-3.43 \mathrm{eV}$. P61 和 PC61BM 优化条件下配合制备 的电池, 效率为 $2.78 \%\left(V_{\mathrm{OC}}=0.86 \mathrm{~V}, J_{\mathrm{SC}}=5.75 \mathrm{~mA}\right.$ $\left.\mathrm{cm}^{-2}, \mathrm{FF}=0.56\right)$. 而用 $\mathrm{PC}_{71} \mathrm{BM}$ 代替 $\mathrm{PC}_{61} \mathrm{BM}$ 时, 效率提 高至 $3.23 \%\left(V_{\mathrm{OC}}=0.86 \mathrm{~V}, J_{\mathrm{SC}}=6.75 \mathrm{~mA} \cdot \mathrm{cm}^{-2}, \mathrm{FF}=\right.$ 0.55). 2010 年 Katz 等 ${ }^{[50]}$ 设计了几种有梯形结构的聚合 物, 而其中聚合物 $\mathbf{P 6 2}$ 是利用 $\mathrm{QO}$ 作为电子受体基团和 梯形寡聚苯撑的交替聚合物. P62 $\left(M_{\mathrm{n}}=7800, \mathrm{PDI}=\right.$ 2.65)膜的吸收谱峰位于 $530 \mathrm{~nm}$, 带隙为 $2.00 \mathrm{eV}$, 其 HOMO 和 LUMO 能级分别为 -5.45 和 $-3.36 \mathrm{eV}$. 利用 $\mathbf{P 6 2}$ 与 $\mathrm{PC}_{61} \mathrm{BM}$ 配合制备的本体异质结器件, 效率为 $2.32 \%\left(V_{\mathrm{OC}}=1.01 \mathrm{~V}, J_{\mathrm{SC}}=5.53 \mathrm{~mA} \cdot \mathrm{cm}^{-2}, \mathrm{FF}=0.42\right)$, 与 $\mathrm{PC}_{71} \mathrm{BM}$ 配合得到的器件效率为 $3.04 \%\left(V_{\mathrm{OC}}=1.00 \mathrm{~V}\right.$, $J_{\mathrm{SC}}=7.57 \mathrm{~mA} \cdot \mathrm{cm}^{-2}, \mathrm{FF}=0.40$ ).

另一常见的氮杂芳环为 thienopyrazine (TP). 早在 2006 年, Janssen 等 ${ }^{[84]}$ 报道了聚合物 P63 和 P64, 发现侧 


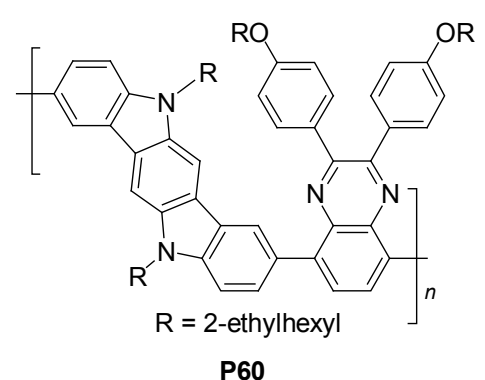

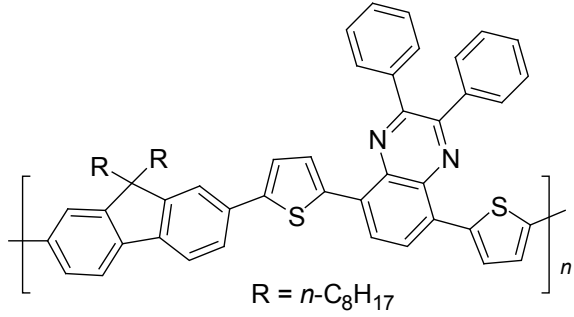

P61

P60

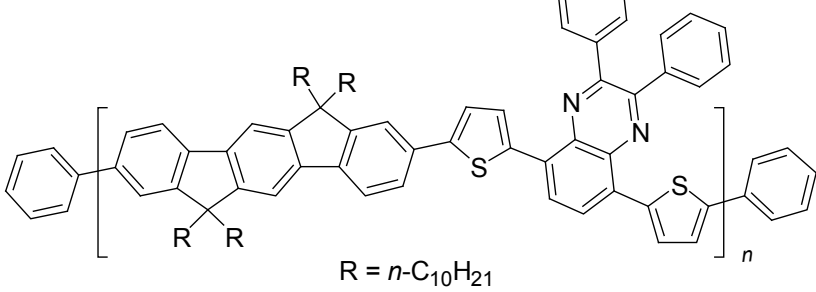

P62

链所处的位置不同对聚合物的光伏性影响很大. P63 和 P64 都是 TP 和二噻吩的交替共聚物, P63 的溶解侧链位 于噻吩环上, 而 $\mathbf{P 6 4}$ 的则位于 $\mathrm{TP}$ 外围的苯环取代基上. 所得 $\mathbf{P 6 3}$ 的分子量为: $M_{\mathrm{n}}=23650, \mathrm{PDI}=4.1$, 而 $\mathbf{P 6 4}$ 的 分子量为: $M_{\mathrm{n}}=52000, \mathrm{PDI}=3.1$, 可见 $\mathbf{P 6 4}$ 比 $\mathbf{P 6 3}$ 的分 子量几乎大了一倍. 但即使如此, P64 和 P63 一样, 在常 用的溶剂中具有很好的溶解度. P63 和 P64 的膜形态吸 收谱带起始点分别为 965 与 $1034 \mathrm{~nm}$, 相应的能隙分别 为 1.28 和 $1.20 \mathrm{eV}$, 表明两者的能隙都很窄, 而 $\mathbf{P 6 4}$ 的比 P63 稍微小一些. 作者认为这是 P64 的分子结构更趋于 平面性所致. 电化学研究发现 P63 的氧化电位比 P64 的 低 $0.18 \mathrm{eV}$, 这是由于其噻吩环侧链为给电子的烷氧基 的原因. 利用两者作为电子给体材料, 和 $1: 4(w / w)$ 的 $\mathrm{PC}_{61} \mathrm{BM}$ 共混, 制备电池器件, P63 的器件效率为 $0.29 \%$ $\left(V_{\mathrm{OC}}=0.39 \mathrm{~V}, J_{\mathrm{SC}}=3.5 \mathrm{~mA} \cdot \mathrm{cm}^{-2}, \mathrm{FF}=0.57\right)$, 而 $\mathbf{P 6 4}$ 制 备的器件效率为 $1.1 \%\left(V_{\mathrm{OC}}=0.56 \mathrm{~V}, J_{\mathrm{SC}}=3.1 \mathrm{~mA} \cdot \mathrm{cm}^{-2}\right.$, $\mathrm{FF}=0.58)$. 值得注意的是, P64 和 P3HT 带隙相差有 0.7 $\mathrm{V}$ 之大 (P3HT: $\left.E_{\mathrm{g}}=1.9 \mathrm{eV}, \mathbf{P 6 4}: E_{\mathrm{g}}=1.20 \mathrm{eV}\right)$, 但和 $\mathrm{PC}_{61} \mathrm{BM}$ 配合制备的电池器件都表现出差不多的开路电 压 $\left(\mathrm{P} 64 / \mathrm{PC}_{61} \mathrm{BM}: V_{\mathrm{OC}}=0.56 \mathrm{~V} ; \mathrm{P} 3 \mathrm{HT} / \mathrm{PC}_{61} \mathrm{BM}: V_{\mathrm{OC}}=\right.$ $0.61 \sim 0.63 \mathrm{~V}) .2008$ 年 $\mathrm{Hou}, \mathrm{Yang}$ 等 $^{[85]}$ 报道了聚合物 P65 $\left(M_{\mathrm{n}}=34600, \mathrm{PDI}=2.2\right)$. 这一聚合物的亮点是能隙 较低, 只有 $1.05 \mathrm{eV}$, 吸收光谱覆盖到 $1000 \mathrm{~nm}$ 以上. 但 是, 由于其 HOMO 能级太高, 为 $-4.65 \mathrm{eV}$, 导致与 $\mathrm{PC}_{61} \mathrm{BM}$ 共混后制备的器件开路电压只有 $0.21 \mathrm{~V}$, 能量 转换效率只有 $0.11 \%\left(J_{\mathrm{SC}}=1.41 \mathrm{~mA} \cdot \mathrm{cm}^{-2}, \mathrm{FF}=0.35\right)$.

噻唑基团含有强吸电子的亚胺键, 是典型的缺电子 基团, 具有强的电子接受能力, 而二噻唑则进一步增强 了这种接受电子的能力. 因此近年来, 陆续有工作利用

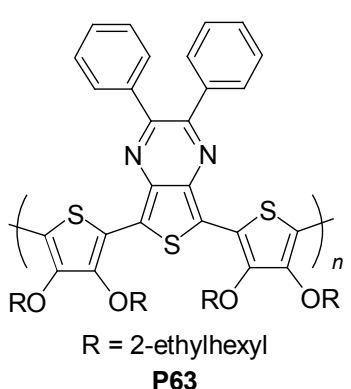

P63

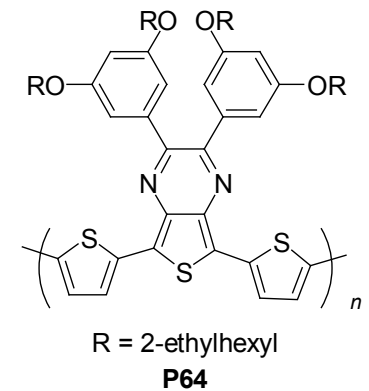

P64

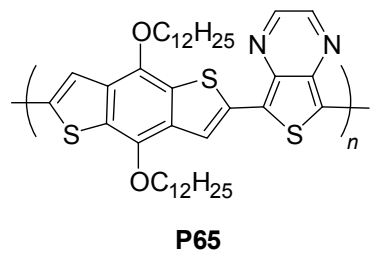

二噻唑作为电子受体基团和各类电子给体基团配合制 备窄带隙聚合物 ${ }^{[86 ~ 89]}$. 例如, 2010 年 $\mathrm{Li}$ 等 ${ }^{[89]}$ 报道的聚 合物 P66, 其主链单元就是含有二噻唑、二噻吩并苯和 噻吩的交替共聚物. 性能研究表明聚合物 P66 $\left(M_{\mathrm{w}}=\right.$ $6400, \mathrm{PDI}=1.95)$ 膜在 $530 \mathrm{~nm}$ 处有最大吸收, 能隙为 $1.97 \mathrm{eV}, \mathrm{HOMO}$ 和 LUMO 能级分别位于 -5.15 和 -2.95 $\mathrm{eV}$. 而且, 进一步 XRD 表征发现聚合物 $\mathbf{P 6 6}$ 链与链间 有较强的相互作用, 测得其 $\pi-\pi$ 堆积间距为 $3.6 \AA$. 利用 P66 和 $\mathrm{PC}_{71} \mathrm{BM}$ 配合制备电池器件, 优化后能量转化率 为 $3.82 \%\left(V_{\mathrm{OC}}=0.86 \mathrm{~V}, J_{\mathrm{SC}}=7.84 \mathrm{~mA} \cdot \mathrm{cm}^{-2}, \mathrm{FF}=0.57\right)$.

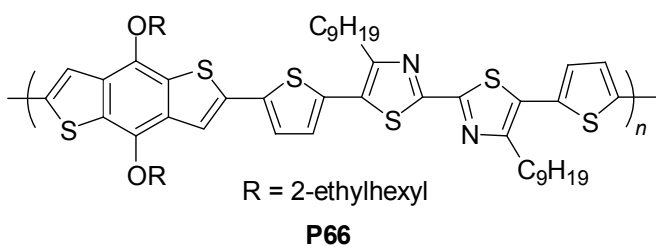




\section{4 含并二噻吩基团}

最近, 并二噻吩(thieno[3,4-b]thiophene, TT)引起研 究者的特别关注. 由于并二噻吩非常容易形成醌式结 构, 聚并二噻吩均聚物本身也是一种带隙极窄的聚合 物 ${ }^{[00]} .2007$ 年, Lu, Yang 等 ${ }^{[91]}$ 首次将 TT 和噻吩配合制备 窄带隙聚合物 P67, 得到的聚合物带隙为 $1.3 \mathrm{eV}$, 但 $\mathrm{HOMO}$ 能级较高, 为 $-4.76 \mathrm{eV}$, 最终和 $\mathrm{PC}_{61} \mathrm{BM}$ 配合制 得的电池, 效率为 $1 \% .2009$ 年 $\mathrm{Chen,} \mathrm{Yu}$ 等 ${ }^{[2]}$ 则将具有 立构规整性的寡聚噻吩和 TT 结合得到聚合物 P68. 性 能研究表明, $\mathbf{P 6 8}$ 的能隙为 $1.62 \mathrm{eV}$, 具有较 P3HT 红移 的吸收谱带, 但 HOMO 能级 $(-4.92 \mathrm{eV})$ 和 P3HT 相似 $(-4.90 \mathrm{eV})$. SCLC 方法测试得到 $\mathbf{P 6 8}$ 膜的空穴迁移率 为 $1.9 \times 10^{-4} \mathrm{~cm}^{2} \cdot \mathrm{V}^{-1} \cdot \mathrm{s}^{-1}$, 略低于 P3HT 膜 $\left(\mu_{\mathrm{h}}=3.30 \times\right.$ $\left.10^{-4} \mathrm{~cm}^{2} \cdot \mathrm{V}^{-1} \cdot \mathrm{s}^{-1}\right)$, 但比不采用立构规整但含同样噻吩 数目的寡聚噻吩的聚合物高 $\left(\mu_{\mathrm{h}}=4.8 \times 10^{-5} \mathrm{~cm}^{2} \cdot \mathrm{V}^{-1}\right.$ ・ $\mathrm{s}^{-1}$ ), 说明立构规整的侧链有利于形成有益电荷传输的 膜结构. 利用 $\mathbf{P 6 8}$ 和 $\mathrm{PC}_{61} \mathrm{BM}$ 制备电池器件, 能量转换 效率为 $2.38 \%\left(V_{\mathrm{OC}}=0.59 \mathrm{~V}, J_{\mathrm{SC}}=10.22 \mathrm{~mA} \cdot \mathrm{cm}^{-2}\right.$, $\mathrm{FF}=0.40)$. 几乎同时, $\mathrm{Yu}$ 研究小组 ${ }^{[33]}$ 报道了极具影响 力的聚合物 $\mathbf{P 6 9}\left(\mathrm{R}^{1}=\right.$ octyl, $\mathrm{R}^{2}=$ dodecyl, $M_{\mathrm{n}}=18300$, $\mathrm{PDI}=1.25) . P 69$ 膜的吸收谱峰位于 $682 \mathrm{~nm}$, 起始位置 为 $774 \mathrm{~nm}$, 相应带隙为 $1.62 \mathrm{eV}$, HOMO 和 LUMO 能级 分别位于 -4.90 和 $-3.20 \mathrm{eV}$. 利用 $\mathbf{P 6 9}$ 和 $\mathrm{PC}_{61} \mathrm{BM}$ 制备 电池器件, 优化后的器件效率为 $4.76 \%\left(V_{\mathrm{OC}}=0.58 \mathrm{~V}\right.$, $\left.J_{\mathrm{SC}}=12.5 \mathrm{~mA} \cdot \mathrm{cm}^{-2}, \mathrm{FF}=0.65\right)$, 改用和 $\mathrm{PC}_{71} \mathrm{BM}$ 配合, 制得的器件效率提高至 $5.30 \%\left(V_{\mathrm{OC}}=0.56 \mathrm{~V}, J_{\mathrm{SC}}=15.0\right.$ $\mathrm{mA} \cdot \mathrm{cm}^{-2}, \mathrm{FF}=0.63$ ). 鉴于 $\mathbf{P 6 9}$ 的 HOMO 能级较高, 他 们 ${ }^{[94]}$ 在 $\mathrm{TT}$ 环上引入吸电子 $\mathrm{F}$ 取代基, 得到聚合物 P70, 有效降低了聚合物的 $\mathrm{HOMO}$ 能级至 $-5.12 \mathrm{eV}$, 从而使 和 $\mathrm{PC}_{61} \mathrm{BM}$ 配合制得的电池器件开路电压提高至 $0.74 \mathrm{~V}$, 带来较好的器件性能 $\left(\mathrm{PCE}=6.1 \%, J_{\mathrm{SC}}=13.0 \mathrm{~mA} \cdot \mathrm{cm}^{-2}\right.$, $\mathrm{FF}=0.614)$. 之后, Hou, $\mathrm{Li}$ 等 ${ }^{[95]}$ 进一步对此聚合物进行 结构改造, 把 TT 环上的酯基取代基换成具有更强吸电 子能力的酰基取代基, 得到聚合物 P71. 性能测试表明, P71 具有和 P68 相类似的光谱性能, 但具有较低的 HOMO 能级, 为 $-5.12 \mathrm{eV}$, 和 P70 相当. 利用 P71 和 $\mathrm{PC}_{71} \mathrm{BM}$ 配合制备的电池, 优化后器件效率为 $6.58 \%$
$\left(V_{\mathrm{OC}}=0.70 \mathrm{~V}, J_{\mathrm{SC}}=14.7 \mathrm{~mA} \cdot \mathrm{cm}^{-2}, \mathrm{FF}=0.64\right)$. 接着, 他 们 ${ }^{[96]}$ 进一步在并二噻吩上引入吸电子的 $\mathrm{F}$ 基团, 得到聚 合物 P72, 进一步降低了聚合物的能级至 $-5.22 \mathrm{eV}$, 从 而提高和 $\mathrm{PC}_{71} \mathrm{BM}$ 配合制备电池器件的开路电压至 0.76 , 效率提高至 $7.73 \%\left(V_{\mathrm{OC}}=0.76 \mathrm{~V}, J_{\mathrm{SC}}=15.2 \mathrm{~mA} \cdot \mathrm{cm}^{-2}, \mathrm{FF}\right.$ $=0.669)$. 这是目前文献报道的最佳值. 最近, 他们 ${ }^{[97]}$ 又对这类聚合物侧链取代基的影响做了详细的研究, 但 效率并没有进一步提升.

\section{5 侧链为受体基团}

从上面的例子可以看出, 目前大多数聚合物给体材 料采用是 $\mathrm{D}-\mathrm{A}$ 交替共聚的策略, $\mathrm{D}$ 和 $\mathrm{A}$ 基团都处于共轭 主链上. 2009 年 Jen 等 ${ }^{[98]}$ 提出 D- $\pi$ 桥-A 侧链(D- $\pi$-bridge$\mathrm{A}$ side chains)的新策略, 采用 $\mathrm{D}$ 基团为主链, 而把 $\mathrm{A}$ 基 团置放在共轭主链侧链, 并通过 $\pi$ 桥连接. 依照此策略, 他们合成了聚合物 P73 $\left(M_{\mathrm{w}}=17700, \mathrm{PDI}=1.7\right)$ 和 $\mathbf{P 7 4}$ $\left(M_{\mathrm{w}}=16300, \mathrm{PDI}=1.6\right)$, 主链皆为富电子的荡和三芳胺 的交替共聚物, 而侧链分别含有强吸电子的双腈基亚甲 基和硫代巴比妥酸根基团. P73 和 P74 的紫外可见吸收 光谱都有两个明显的吸收峰, 在 $385 \mathrm{~nm}$ 处的吸收峰是 共轭主链的 $\pi-\pi *$ 造成的，而另一个位于可见光区域的吸 收峰是主链和侧链间分子内电荷转移形成的. 根据吸收 谱带的起始点, 测得 $\mathbf{P 7 3}$ 的带隙为 $1.87 \mathrm{eV}$, 而 P74 的为 $1.76 \mathrm{eV}$. 而且由于主链结构一致, P73 和 P74 具有非常 相似的氧化电位, 导致它们的 HOMO 能级相近, 分别为 -5.30 和 $-5.26 \mathrm{eV}$. 更重要的是, 这两个聚合物都具有 较强的空穴传输能力, 其空穴迁移率分别为 $5.27 \times 10^{-4}$ 和 $1.16 \times 10^{-3} \mathrm{~cm}^{2} \cdot \mathrm{V}^{-1} \cdot \mathrm{s}^{-1}$, 高于 P3HT. 利用 $\mathbf{P 7 3}$ 和 P74 分别跟 $\mathrm{PC}_{71} \mathrm{BM}$ 配合制备电池, 得到的器件具有较高的 开路电压 $(0.99 \mathrm{~V})$, 效率都比较高, 分别为 $4.37 \%\left(V_{\mathrm{OC}}=\right.$ $\left.0.99 \mathrm{~V}, J_{\mathrm{SC}}=9.62 \mathrm{~mA} \cdot \mathrm{cm}^{-2}, \mathrm{FF}=0.50\right)$ 和 $4.19 \%\left(V_{\mathrm{OC}}=\right.$ $\left.0.99 \mathrm{~V}, J_{\mathrm{SC}}=9.61 \mathrm{~mA} \cdot \mathrm{cm}^{-2}, \mathrm{FF}=0.46\right)$. 作者认为这种设 计策略, 所得的材料具有二维共轭体系, 由此可带来各 向均衡的电荷传输能力. 而且, 此类聚合物的吸收谱带 容易通过延长侧链或采用更有效的 $\pi$ 桥来调节, 而基本 保持主链的结构不变. 另外, 主链的结构单元皆为富电 子基团, 有利于空穴的传输.

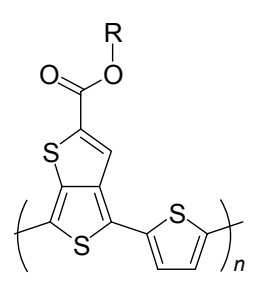

P67

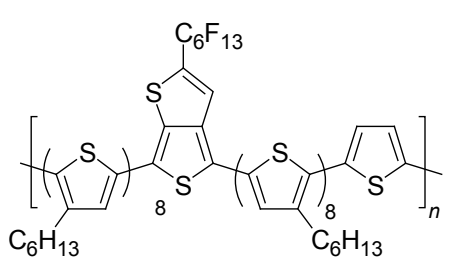

P68

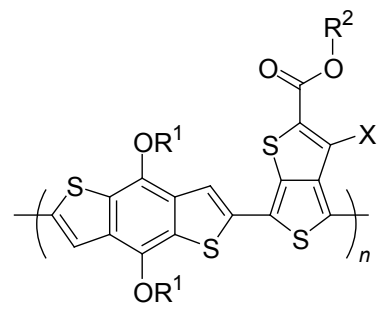

P69 $X=H \quad$ P70 X = F

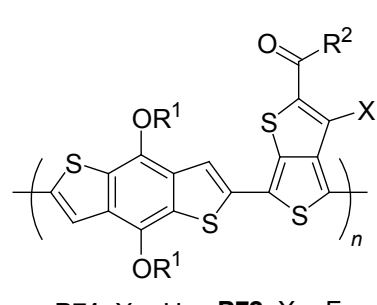

P71 $X=H \quad$ P72 $X=F$ 


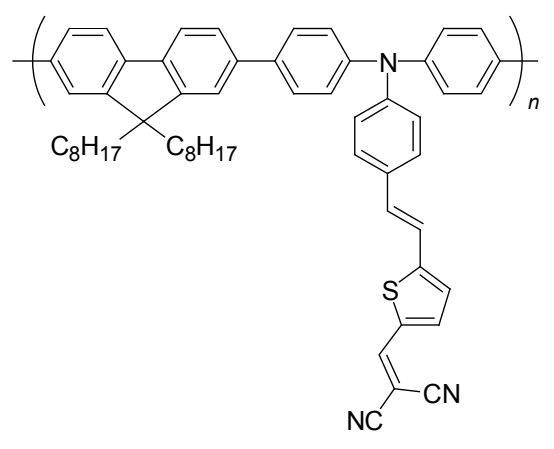

P73

\section{6 主链中含有金属的聚合物}

在有机光电基团的激发态中, 单线态寿命很短, 而 三线态则有较长的寿命. 基于重金属元素具有较高的单 线态和三线态之间的系间转化效率, 将重金属元素引入 至共轭主链, 有望提高共轭主链激发态的寿命, 从而有 利于光电转化. Wong 和 Djurišic 等 ${ }^{[99}$ 报道了聚合物 P75 (聚合度 $\approx 22$ ), 主链单元除了含噻吩和苯并噻二唑基团 外, 还含有 Pt. 聚合物 P75 的二氯甲烷溶液呈紫色, 吸 收峰位于 $554 \mathrm{~nm}$, 带隙为 $1.85 \mathrm{eV}$. 但是 P75 的荧光寿命 很短 (ns 量级), 不像其它的 Pt 炔烃衍生物. 而且, P75 在 低温下没有电子振动结构. 这些现象说明在 P75 的激发 态主要是单线态, 而非三线态. 电化学测得 P75 的 HOMO 和 LUMO 能级分别为 -5.37 和 $-3.14 \mathrm{eV}$. 利用 P75 作为电子给体, 和 $\mathrm{PC}_{61} \mathrm{BM}$ 配合制备本体异质结电 池, 优化后的光电转换效率为 $4.93 \%\left(V_{\mathrm{OC}}=0.82 \mathrm{~V}\right.$, $\left.J_{\mathrm{SC}}=15.43 \mathrm{~mA} \cdot \mathrm{cm}^{-2}, \mathrm{FF}=0.39\right)$, 而同等条件下制备的 $\mathrm{P} 3 \mathrm{HT} / \mathrm{PC}_{61} \mathrm{BM}$ 的器件效率只有 $1.6 \%$, 表明 $\mathbf{P 7 5}$ 是一类 很有潜力的聚合物给体材料. 同年, 他们 ${ }^{[86]}$ 还报道了聚 合物 P76 P79. 这里, 他们采用二噻唑为电子受体基 团, 而寡聚噻吩和炔基 Pt 为给体基团. 性能研究表明, 这些聚合物的能隙都在 $2 \mathrm{eV}$ 以上, 但随着噻吩数目的 增加而降低. 电化学测试这些聚合物具有较低的 HOMO 能级(P76: $-5.91 \mathrm{eV} ;$ P77: $-5.82 \mathrm{eV;} \mathrm{P78:}$ $-5.79 \mathrm{eV} ; \mathbf{P 7 9}$ : $-5.71 \mathrm{eV})$. 利用这些聚合物和 $\mathrm{PC}_{61} \mathrm{BM}$ 配合制备电池器件, 性能较好的是含 2 个以上 噻吩基团的聚合物 P78 和 P79, 能量转换效率分别为 $2.14 \%\left(V_{\mathrm{OC}}=0.83 \mathrm{~V}, J_{\mathrm{SC}}=6.93 \mathrm{~mA} \cdot \mathrm{cm}^{-2}, \mathrm{FF}=0.38\right)$ 和 $2.50 \%\left(V_{\mathrm{OC}}=0.88 \mathrm{~V}, J_{\mathrm{SC}}=6.50 \mathrm{~mA} \cdot \mathrm{cm}^{-2}, \mathrm{FF}=0.44\right)$, 但 P77 和 P78 的效率低于 $1 \% .2008$ 年, Jen 等 ${ }^{[100]}$ 报道了含 炔基 $\mathrm{Pt}$ 的聚合物 P80. 他们考察了三个不同侧链的 P80, 发现当 $\mathrm{R}^{1}$ 为正辛基, 而 $\mathrm{R}_{2}$ 为 $\mathrm{P}(\mathrm{Et})_{3}$, 性能最佳. 此聚合 物的能隙为 $1.81 \mathrm{eV}$, 而 $\mathrm{HOMO}$ 能级为 $-5.14 \mathrm{eV}$. 虽然, P80 膜是无定形态, 但 FET 测试表明其具有较高的载流
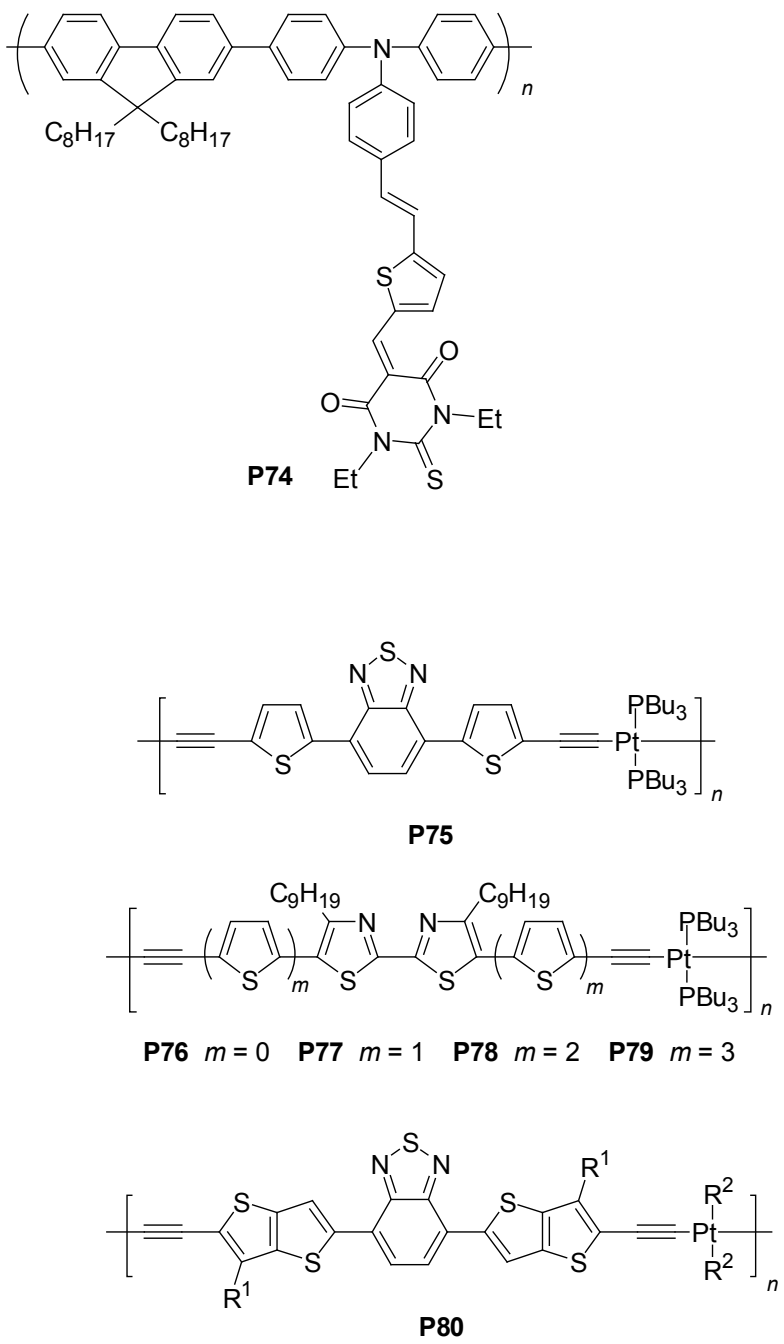

子迁移率, 为 $0.89 \times 10^{-2} \mathrm{~cm}^{2} \cdot \mathrm{V}^{-1} \cdot \mathrm{s}^{-1}$. 利用此聚合物和 $\mathrm{PC}_{61} \mathrm{BM}$ 配合制得的电池器件, 能量转换效率为 $2.22 \%$ $\left(V_{\mathrm{OC}}=0.793 \mathrm{~V}, J_{\mathrm{SC}}=6.57 \mathrm{~mA} \cdot \mathrm{cm}^{-2}, \mathrm{FF}=0.494\right)$, 和 $\mathrm{PC}_{71} \mathrm{BM}$ 配合, 则提高至 $3.73 \%\left(V_{\mathrm{OC}}=0.787 \mathrm{~V}, J_{\mathrm{SC}}=\right.$ $\left.9.61 \mathrm{~mA} \cdot \mathrm{cm}^{-2}, \mathrm{FF}=0.493\right)$.

\section{3 结论与展望}

基于有机太阳能电池光电转换的基本原理，理想的 聚合物给体材料应该具备: (1)覆盖从紫外至近红外区域 宽广的吸收谱带; (2)具备理想的 HOMO 和 LUMO 能级. 假如使用 PCBM 作为电子受体材料, 聚合物的 HOMO 能级低于 $-5.20 \mathrm{eV} ;(3)$ 聚合物膜的微结构具备强的载 流子传输能力, 即具备高的载流子迁移率; (4)和 PCBM 共混后容易形成有利于光电转化的微结构, 比如宽广的 异质结界面，双连续的 $\mathrm{D}$ 和 $\mathrm{A}$ 微相. 近年来聚合物给体 材料的研制, 主要关注材料的光谱吸收能力, 开发了绚 丽多彩的各种窄带隙材料, 较好的解决了充分利用太阳 光能的问题. 基于这些材料制备的电池器件, 光电转换 
效率已取得较大的进步，从几年前徘徊在 5\% ${ }^{[23]}$ 到现在 突破 $9 \%{ }^{[5]}$. 但是, 这个效率仍然不能满足实用化的要 求. 今后的材料设计, 除了继续关注材料的光吸收能力 外, 应该同时考虑材料凝聚态结构和载流子迁移能力. 从文中所枚举的例子可以看出, 影响这方面的因素很 多, 除了制备和后处理过程工艺的影响外, 材料自身的 化学结构十分重要. 在这方面, 特别要关注侧链基团的 影响. 文中多个例子表明侧链基团的种类、长短、支化 度、位置和朝向等对材料最终的性能影响很大. 当然, 整体材料的化学结构一凝聚态结构一性质间的基本规律, 尚未明朗, 需要进一步深入研究.

\section{References}

[1] Tang, C. W. Appl. Phys. Lett. 1986, 48, 183.

[2] (a) Yu, G.; Gao, J.; Hummelen, J. C.; Wudl, F.; Heeger, A. J. Science 1995, 270, 1789 .

(b) Halls, J. J. M.; Walsh, C. A.; Greenham, N. C.; Marseglia, E. A.; Friend, R. H.; Moratti, S. C.; Holmes, A. B. Nature 1995, 376, 498.

[3] (a) Thompson, B. C.; Fréchet, J. M. J. Angew. Chem., Int. Ed. 2008, 47,58 .

(b) Cheng, Y.-J.; Yang, S.-H.; Hsu, C.-S. Chem. Rev. 2009, 109, 5868 .

(c) Brabec, C. J.; Gowrisanker, S.; Halls, J. J. M.; Laird, D.; Jia, S.; Williams, S. P. Adv. Mater. 2010, 22, 3839.

[4] Hummelen, J. C.; Knight, B. W.; LePeg, F.; Wudl, F. J. Org. Chem. 1995, 60, 532

[5] Service, R. F. Science 2011, 332, 293.

[6] Brroughes, J. H.; Bradeley, D. D. C. Nature 1990, 347, 539.

[7] (a) Becker, H.; Spreitzer, H.; Ibrom, K.; Kreuder, W. Macromolecules 1999, 32, 4925.

(b) Chen, Z. K.; Lee, N. H. S.; Huang, W.; Xu, Y. S.; Cao, Y. Macromolecules 2003, 36, 1009.

(c) Bao, Z.; Chen, Y.; Cai, R.; Yu, L. Macromolecules 1993, 26, 5281 .

(d) Tajima, K.; Suzuki, Y.; Hashimoto, K. J. Phys. Chem. C 2008, 112, 8507 .

(e) Tan, Z.; Tang, R.; Zhou, E.; He, Y.; Yang, C.; Xi, F.; Li, Y. J. Appl. Polym. Sci. 2008, 107, 514.

(f) Wen, S.; Pei, J.; Zhou, Y.; Xue, L.; Xu, B.; Li, Y.; Tian, W. J. Polym. Sci., Part A: Polym. Chem. 2009, 47, 1003.

[8] Grobert, N.; Hsu. W. K.; Zhu, Y. Q. Appl. Phys. Lett. 1999, 75, 3363.

[9] Neef, C. J.; Ferraris, J. P. Macromolecules 2000, 33, 2311.

[10] Sariciftci, N. S.; Zhang, C.; Srdanov, V. I. Appl. Phys. Lett. 1993, 62,585 .

[11] Shaheen, S. E.; Brabec, C. J.; Sariciftci, N. S.; Padinger, F.; Fromherz, T.; Hunnelen, J. C. Appl. Phys. Lett. 2001, 78, 841.

[12] Veenstra, S. C.; Verhees, W. J. H.; Kroon, J. M.; Koetse, M. M.; Sweelssen, J.; Bastiaansen, J. J. A. M.; Schoo, H. F. M.; Yang, X.; Alexeev, A.; Loos. J.; Schubert, U. S.; Wienk, M. M. Chem. Mater. 2004, 16, 2503.

[13] Suzuki, Y.; Hashimoto, K.; Tajima, K. Macromolecules 2007, 40, 6521.

[14] Wan, W. C.; Antoniadis, H.; Choong, V. E.; Razafitrimo, H.; Gao, Y.; Feld, W. A.; Heieh, B. R. Macromolecules. 1997, 30, 6567.

[15] Yu, G.; Heeger, A. J. J. Appl. Phys. 1995, 78, 4510.
[16] Thompson, B. C.; Kim, Y.-G.; Mccarley, T. D.; Reynolds, J. R. J. Am. Chem. Soc. 2006, 128, 12714.

[17] Shen, P.; Sang, G.; Lu, J.; Zhao, B.; Wan, M.; Zou, Y.; Li, Y.; Tan, S. Macromolecules 2008, 41, 5716.

[18] (a) Yamamoto, T.; Sanechika, K.; Yamamoto, A. J. Polym. Sci., Polym. Lett. Ed. 1980, 18, 9.

(b) Kaneto, K.; Kohno, Y.; Yoshino, K.; Inuishi, Y. J. Chem. Soc., Chem. Commun. 1983, 382.

(c) Waltman, R. J.; Bargon, J.; Diaz, A. F. J. Phys. Chem. 1983, 87, 1459.

[19] Jen, K. Y.; Miller, G. G.; Elsenbaumer, R. L. J Chem Soc., Chem Commun. 1986, 1346.

[20] Glenisa, S.; Horowitza, G.; Tourillona, G.; Garniera, F. Thin Solid Films 1984, 111, 93.

[21] Sariciftci, N. S.; Hebger, A. J. Int. J. Mod. Phys. B 1994, 8, 237.

[22] Roman, L. S.; Andersson, M. R.; Yohannes, T.; Inganás, O. $A d v$. Mater. 1997, 9, 1164.

[23] (a) Ma, W.; Yang, C.; Gong, X.; Lee, K.; Heeger, A. J. Adv. Funct. Mater. 2005, 15, 1617.

(b) Reyes-Reyes, M.; Kim, K.; Carroll, D. L. Appl. Phys. Lett. 2005, 87, 083506.

[24] (a) Kim, K.; Liu, J.; Namboothiry, M. A. G.; Carroll, D. L. Appl. Phys. Lett. 2007, 90, 163511.

(b) Zhao, G.; He, Y.; Li, Y. Adv. Mater. 2010, 22, 4355.

[25] Nguyen, L. H.; Hoppe, H.; Erb, T.; Günes, S.; Gobsch, G.; Sariciftci, N. S. Adv. Funct. Mater. 2007, 17, 1071.

[26] Kim, Y.; Cook, S.; Tuladhar, S. M.; Choulis, S. A.; Nelson, J.; Durrant, J. R.; Bradley, D. D. C.; Giles, M.; Mcculloch, I.; Ha, C.-S.; Ree, M. Nat. Mater. 2006, 5, 197.

[27] Sivula, K.; Luscombe, C. K.; Thompson, B. C.; Fréchet, J. M. J. J. Am. Chem. Soc. 2006, 128, 13988.

[28] Woo, C. H.; Thompson, B. C.; Kim, B. J.; Toney, M. F.; Fréchet, J. M. J. J. Am. Chem. Soc. 2008, 130, 16324.

[29] Shi, C.; Yao, Y.; Yang, Y.; Pei, Q. J. Am. Chem. Soc. 2006, 128, 8980.

[30] Hou, J.; Tan, Z.; Yan, Y.; He, Y.; Yang, C.; Li, Y. J. Am. Chem. Soc. 2006, 128, 4911.

[31] Havinga, E. E.; ten Hoeve, W.; Wynberg, H. Polym. Bull. 1992, 29, 119.

[32] (a) Shaheen, S. E.; Vangeneugden, D.; Kiebooms, R.; Vanderzande, D.; Fromherz, T.; Padinger, F.; Brabec, C. J.; Sariciftci, N. S. Synth. Met. 2001, 121, 1583.

(b) van Duren, J. K. J.; Dhanabalan, A.; van Hal, P. A.; Janssen, R. A. J. Synth. Met. 2001, 121, 1587.

[33] Brabec, C. J.; Winder, C.; Sariciftci, N. S.; Hummelen, J. C.; Dhanabalan, A.; van Hal, P. A.; Janssen, R. A. I. Adv. Funct. Mater. 2002, 12, 709.

[34] Svensson, M.; Zhang, F.; Inaganäs, O.; Andersson, M. R. Synth. Met. 2003, 135 136, 137.

(b) Svensson, M.; Zhang, F.; Veenstra, S. C.; Verhees, W. J. H.; Hummelen, J. C.; Kroon, J. M.; Inaganäs, O.; Andersson, M. R. Adv. Mater. 2003, 15, 988.

[35] Zhou, Q.; Hou, Q.; Zheng, L.; Deng, X.; Yu, G.; Cao, Y. Appl. Phys. Lett. 2004, 84, 1653.

[36] Wang, E.; Wang, L.; Lan, L.; Luo, C.; Zhuang, W.; Peng, J.; Cao, Y. Appl. Phys. Lett. 2008, 92, 033307.

[37] Boudreault, P.-L. T.; Michaud, A.; Leclerc, M. Macromol. Rapid Commun. 2007, 28, 2176.

[38] Allard, N.; Ach R. B.; Gendron, D.; Boudreault, P.-L. T.; Tessier, C.; Alem, S.; Tse, S.-C.; Tao, Y.; Leclerc, M. Macromolecules 2010, 43, 2328.

[39] Blouin, N.; Michaud, A.; Leclerc, M. Adv. Mater. 2007, 19, 2295. 
[40] Park, S. H.; Roy, A.; Beaupre, S.; Cho, S.; Coates, N.; Moon, J. S.; Moses, D.; Leclerc, M.; Lee, K.; Heeger, A. J. Nat. Photon 2009, 3, 297.

[41] Zhu, Z.; Waller, D.; Gaudiana, R.; Morana, M.; Mühlbacher, D.; Scharber, M.; Brabec, C. Macromolecules 2007, 40, 1981.

[42] Mühlbacher, D.; Scharber, M.; Morana, M.; Zhu, Z.; Waller, D.; Gaudiana, R.; Brabec, C. Adv. Mater. 2006, 18, 2884.

[43] Peet, J.; Kim, J. Y.; Coates, N. E.; Ma, W. L.; Moses, D.; Heeger, A. J.; Bazan, G. C. Nat. Mater. 2007, 6, 497.

[44] Hou, J.; Chen, H.-Y.; Zhang, S.; Li, G.; Yang, Y. J. Am. Chem. Soc. 2008, 130, 16144.

[45] Coffin, R. C.; Peet, J.; Rogers, J.; Bazan, G. C. Nat. Chem. 2009, 1, 657

[46] Yue, W.; Zhao, Y.; Shao, S.; Tian, H.; Xie, Z.; Geng, Y.; Wang, F. J. Mat. Chem. 2009, 19, 2199.

[47] Moulé, A. J.; Tsami, A.; Bünnagel, T. W.; Forster, M.; Kronenberg, N. M.; Scharber, M.; Koppe, M.; Morana, M.; Brabec, C. J.; Meerholz, K.; Scherf, U. Chem. Mater. 2008, 20, 4045.

[48] Liao, L.; Dai, L.; Smith, A.; Durstock, M.; Lu, J.; Ding, J.; Tao, Y. Macromolecules 2007, 40, 9406.

[49] Zhou, E.; Nakamura, M.; Nishizawa, T.; Zhang, Y.; Wei, Q.; Tajima, K.; Yang, C.; Hashimoto, K. Macromolecules 2008, 41, 8302.

[50] Zheng, Q.; Jung, B. J.; Sun, J.; Katz, H. E. J. Am. Chem. Soc. 2010, $132,5394$.

[51] Lu, J.; Liang, F.; Drolet, N.; Ding, J.; Tao, Y.; Movileanua, R. Chem. Commun. 2008, 5315.

[52] Zhou, E.; Yamakawa, S.; Zhang, Y.; Tajima, K.; Yang, C.; Hashimoto, K. J. Mater. Chem. 2009, 19, 7730.

[53] Chen, Y.-C.; Yu, C.-Y.; Fan, Y.-L.; Hung, L.-I; Chen, C.-P.; Ting, C. Chem. Commun. 2010, 6503.

[54] Yue, W.; Zhao, Y.; Tian, H.; Song, D.; Xie, Z.; Yan, D.; Geng, Y.; Wang, F. Macromolecules 2009, 42, 6510

[55] Liang, F.; Lu, J.; Ding, J.; Movileanu, R.; Tao, Y. Macromolecules 2009, 42, 6107.

[56] Ong, K.-H.; Lim, S.-L.; Tan, H.-S.; Wong, H.-K.; Li, J.; Ma, Z.; Moh, L. C. H.; Lim, S.-H.; de Mello, J. C.; Chen, Z.-K. Adv. Mater. 2011, 23, 1409

[57] Qin, R.; Li, W.; Li, C.; Du, C.; Veit, C.; Schleiermacher, H.-F.; Andersson, M.; Bo, Z.; Liu, Z.; Inganäs, O.; Wuerfel, U.; Zhang, F. J. Am. Chem. Soc. 2009, 131, 14612.

[58] Helgesen, M.; Gevorgyan, S. A.; Krebs, F. C.; Janssen, R. A. J. Chem. Mater. 2009, 21, 4669.

[59] Zhan, X.; Tan, Z. A.; Domercq, B.; An, Z.; Zhang, X.; Barlow, S.; Li, Y.; Zhu, D.; Kippelen, B.; Marder, S. R. J. Am. Chem. Soc. 2007, 129, 7246.

[60] Zhan, X.; Tan, Z. A.; Zhou, E.; Li, Y.; Misra, R.; Grant, A.; Domercq, B.; Zhang, X.-H.; An, Z.; Zhang, X.; Barlow, S.; Kippelen, B.; Marder, S. R. J. Mater. Chem., 2009, 19, 5794.

[61] Hou, J.; Zhang, S.; Chen, T. L.; Yang, Y. Chem. Commun. 2008, 6034.

[62] Chen, J.; Shi, M. M.; Hu, X.-L.; Wang, M.; Chen, H.-Z. Polymer 2010, 51, 2897.

[63] Yuan, Z.; Xiao, Y.; Yang, Y.; Xiong, T. Macromolecules 2011, 44, 1788.

[64] Piyakulawat, P.; Keawprajak, A.; Chindaduang, A.; Helfer, A.; Asawapirom, U. e-Polymers 2010, 071.

[65] Bürgi, L.; Turbiez, M.; Pfeiffer, R.; Bienewald, F.; Kirner, H.-J.; Winnewisser, C. Adv. Mater. 2008, 20, 2217.

[66] Wienk, M. M.; Turbiez, M.; Gilot, J.; Janssen, R. A. J. Adv. Mater. 2008, 20, 2556

[67] Zoombelt, A. P.; Mathijssen, S. G. J.; Turbiez, M. G. R.; Wienka, M. M.; Janssen, R. A. J. J. Mater. Chem. 2010, 20, 2240.
[68] Bijleveld, J. C.; Zoombelt, A. P.; Mathijssen, S. G. J.; Wienk, M. M.; Turbiez, M.; Leeuw, D. M.; Janssen, R. A. J. J. Am. Chem. Soc. 2009, 131, 16616

[69] Chen, G.-Y.; Chiang, C.-M.; Kekuda, D.; Lan, S.-C.; Chu, C.-W.; Wei, K.-H. J. Polym. Sci. Part A: Polym. Chem. 2010, 48, 1669.

[70] Zou, Y.; Gendron, D.; Badrou-Aïch, R.; Najari, A.; Tao, Y.; Leclerc, M. Macromolecules 2009, 42, 2891.

[71] Zhou, E.; Wei, Q.; Yamakawa, S.; Zhang, Y.; Tajima, K.; Yang, C.; Hashimoto, K. Macromolecules 2009, 42, 821.

[72] Kanimozhi, C.; Balraju, P.; Sharma, G. D.; Patil, S. J. Phys. Chem. $B$ 2010, 114, 3095.

[73] Woo, C. H.; Beaujuge, P. M.; Holcombe, T. W.; Lee, O. P.; Fréchet, J. M. J. J. Am. Chem. Soc. 2010, 132, 15547.

[74] Zou, Y.; Najari, A.; Berrouard, P.; Beaupré, S.; Aïch, B. R.; Tao, Y.; Leclerc, M. J. Am. Chem. Soc. 2010, 132, 5330.

[75] Zhang, Y.; Hau, S. K.; Yip, H.-L.; Sun, Y.; Acton, O.; Jen, A. K.-Y. Chem. Mater. 2010, 22, 2696.

[76] Zhang, G.; Fu, Y.; Zhang, Q.; Xie, Z. Chem. Commun. 2010, 4997.

[77] Piliego, C.; Holcombe, T. W.; Douglas, J. D.; Woo, C. H.; Beaujuge, P. M.; Fréchet, J. M. J. J. Am. Chem. Soc. 2010, 132, 7595.

[78] Yuan, M.-C.; Chiu, M.-Y.; Liu, S.-P.; Chen, C.-M.; Wei, K.-H. Macromolecules 2010, 43, 6936.

[79] Guo, X.; Xin, H.; Kim, F. S.; Liyanage, A. D. T.; Jenekhe, S. A. Watson, M. D. Macromolecules 2011, 44, 269.

[80] Chu, T.-Y.; Lu, J.; Beaupre, S.; Zhang, Y.; Pouliot, J.-R.; Wakim, P.; Zhou, J.; Leclerc, M.; Li, Z.; Ding, J.; Tao, Y. J. Am. Chem. Soc. 2011, 133, 4250.

[81] Zhang, G.; Fu, Y.; Xie, Z.; Zhang, Q. Macromolecules 2011, 44, 1414.

[82] Tsai, J. H.; Chueh, C. C.; Lai, M. H.; Wang, C. F.; Chen, W. C.; Ko, B. T.; Ting, C. Macromolecules 2009, 42, 1897.

[83] Zhou, E.; Cong, J.; Tajima, K.; Hashimoto, K. Chem. Mater. 2010, $22,4890$.

[84] Wienk, M. M.; Turbiez, M. G. R.; Struijk, M. P.; Fonrodona, M.; Janssen, R. J. Appl. Phys. Lett. 2006, 88, 153511.

[85] Hou, J.; Park, M.-H.; Zhang, S.; Yao, Y.; Chen, L.-M.; Li, J.-H.; Yang, Y. Macromolecules 2008, 41, 6012.

[86] Wong, W.-Y.; Wang, X.-Z.; He, Z.; Chan, K.-K.; Djurišić, A. B.; Cheung, K.-Y.; Yip, C.-T.; Ng, A. M.-C.; Xi, Y. Y.; Mak, C. S. K.; Chan, W.-K. J. Am. Chem. Soc. 2007, 129, 14372.

[87] Li, K.-C.; Huang, J.-H.; Hsu, Y.-C.; Huang, P.-J.; Chu, C.-W.; Lin, J.-T.; Ho, K.-C.; Wei, K.-H.; Lin, H.-C. Macromolecules 2009, 42, 3681.

[88] Zhang, M.; Fan, H.; Guo, X.; He, Y.; Zhang, Z.; Min, J.; Zhang, J.; Zhao, G.; Zhan, X.; Li, Y. Macromolecules 2010, 43, 5706.

[89] Zhang, M.; Fan, H.; Guo, X.; He, Y.; Zhang, Z.-G.; Min, J.; Zhang, J.; Zhao, G.; Zhan, X.; Li, Y. Macromolecules. 2010, 43, 8714.

[90] (a) Lee, K. H.; Sotzing, G. A. Macromolecules 2001, 34, 5746. (b) Sotzing, G. A.; Lee, K. H. Macromolecules 2002, 35, 7281.

[91] Yao, Y.; Liang, Y.; Shrotriya, V.; Xiao, S.; Yu, L.; Yang, Y. Adv. Mater. 2007, 19, 3979.

[92] Liang, Y.; Feng, D.; Guo, J.; Szarko, J. M.; Ray, C.; Chen, L. X.; $\mathrm{Yu}, \mathrm{L}$. Macromolecules 2009, 42, 1091

[93] Liang, Y.; Wu, Y.; Feng, D.; Tsai, S.-T.; Son, H.-J.; Li, G.; Yu, L. J. Am. Chem. Soc. 2009, 131, 56.

[94] Liang, Y.; Feng, D.; Wu, Y.; Tsai, S.-T.; Li, G.; Ray, C.; Yu, L. J. Am. Chem. Soc. 2009, 131, 7792.

[95] Hou, J.; Chen, H.-Y.; Zhang, S.; Chen, R. I.; Yang, Y.; Wu, Y.; Li, G. J. Am. Chem. Soc. 2009, 131, 15586.

[96] Chen, H.-Y.; Hou, J.; Zhang, S.; Liang, Y.; Yang, G.; Yang, Y.; Yu, L.; Li, G. Nat. Photon 2009, 3, 649. 
[97] Liang, B. Y.; Xu, Z.; Xia, J.; Tsai, S. T.; Wu, Y.; Li, G.; Ray, C.; Yu, L. Adv. Mater. 2010, 22, E135.

[98] Huang, F.; Chen, K.-S.; Yip, H.-L.; Hau, S. K.; Acton, O.; Zhang, Y.; Luo, J.; Jen, A. K.-Y. J. Am. Chem. Soc. 2009, 131, 13886.

[99] Wong, W.-Y.; Wang, X.-Z.; He, Z.; Djurišić, A. B.; Yip, C.-T.;
Cheung, K.-Y.; Wang, H.; Mak, C. S. K.; Chan, A. W.-K. Nat. Mater. 2007, 6, 521.

[100] Baek, N. S.; Hau, S. K.; Yip, H.-L.; Acton, O.; Chen, K.-S.; Jen, A. K.-Y. Chem. Mater. 2008, 20, 5734. 